\title{
In-Silico Validation and Development of Chlorogenic Acid (CGA) Loaded Polymeric Nanoparticle for Targeting Neurodegenerative Disorders
}

\author{
Vinayak Agarwal', Shriya Agarwal', Ramneek Kaur'2, Pranav Pancham¹, Harleen Kaur'3, \\ Siddhi Bhardwaj", Manisha Singh ${ }^{*}$ (i)
}

\author{
${ }^{1}$ Department of Biotechnology, Jaypee Institute of Information Technology (JIIT), Noida, U.P., India \\ ${ }^{2}$ School of Medicine, Western Sydney University, Campbelltown, New South Wales, Australia \\ ${ }^{3}$ Amity Institute of Biotechnology, Amity University, Noida, U.P., India \\ Email: *manishasingh1295@gmail.com
}

How to cite this paper: Agarwal, V., Agarwal, S., Kaur, R., Pancham, P., Kaur, H., Bhardwaj, S. and Singh, M. (2020) In-Silico Validation and Development of Chlorogenic Acid (CGA) Loaded Polymeric Nanoparticle for Targeting Neurodegenerative Disorders. Journal of Biomaterials and Nanobiotechnology, 11, 279-303.

https://doi.org/10.4236/jbnb.2020.114018

Received: September 8, 2020

Accepted: October 18, 2020

Published: October 21, 2020

Copyright $\odot 2020$ by author(s) and Scientific Research Publishing Inc. This work is licensed under the Creative Commons Attribution International License (CC BY 4.0).

http://creativecommons.org/licenses/by/4.0/

\begin{abstract}
Background: Recent decades witnessed a significant growth in terms of phytocompounds based therapeutics, extensively explored for almost all types of existing disorders. They have also been widely investigated in Neurodegenerative disorders (NDDs) and Chlorogenic acid (CGA), a polyphenolic compound having potential anti-inflammatory and anti-oxidative properties, emerged as a promising compound in ameliorating NDDs. Owing to its poor stability, bioavailability and release kinetics, CGA needed a suitable nanocarrier based pharmaceutical design for targeting NDDs. Objective: The current study is aimed at the in-silico validation of CGA as an effective therapeutic agent targeting various NDDs followed by the fabrication of polymeric nanoparticles-based carrier system to overcome its pharmacological limitations and improve its stability. Methods: A successful in-silico validation using molecular docking techniques along with synthesis of CGA loaded polymeric nanoparticles (CGA-NPs) by ionic gelation method was performed. The statistical optimisation of the developed CGA-NPs was done by Box Behnken method and then the optimized formulation of CGA-NPs was characterised using particle size analysis (PSA), Transmission electron microscopy (TEM), Fourier Transform Infrared spectroscopy (FTIR) along with in-vitro release kinetics analysis. Results \& Conclusion: The results attained exhibited average particle size of $101.9 \pm 1.5 \mathrm{~nm}$, Polydispersibility (PDI) score of 0.065 and a ZP of $-17.4 \mathrm{mV}$. On a similar note, TEM results showed a size range of CGA-NPs between $90-110 \mathrm{~nm}$ with a spherical shape of NPs. Also, the data from in-vitro re-
\end{abstract}


lease kinetics showed a sustained release of CGA from the NPs following the first-order kinetics suggesting the appropriate designing of nanoformulation.

\section{Keywords}

Antioxidant, Anti-Inflammatory, Polymeric Nanoparticles, Release Kinetics, Box Behnken Design, Molecular Docking, Particle Size Analysis

\section{Introduction}

Neurodegenerative disorders (NDDs) is a collective term given to set of neurological disorders that exhibits progressive degeneration of neurons (motor or sensory); including developmental and psychiatric strains [1]. They occur when neural system in brain and spinal cord starts to gradually deteriorate, resulting in compromised cellular functioning and eventually leading to neuronal death. Most of the NDDs arise as a consequence of an intricate cascade of pathological events, such as neuro-inflammatory changes, oxidative stress, mitochondrial dysfunction and protein aggregations [2]. Many research studies have shown that, in state of higher oxidative stress, the excessive reactive species formed, induces disruptions in intra-cellular signalling further causing dysregulation of the inflammatory responses. Thereafter, there is an increased generation of many inflammatory mediators causing the release of pro-inflammatory cytokines (IL-4, IL-6, IL-10, IL-1 $\beta$ ), tumor necrosis factor (TNF $\alpha$ ) activation along with activated inflammasomes and these mediators are marked, mostly as a sign of mitochondrial-derived oxidative stress [3]. Out of all other forms, IL-10 cytokine is primarily responsible for the neuroprotection and neuronal survival and is a known anti-inflammatory mediator that involves the reduction of pro-inflammatory molecules in NDDs as the natural response towards the pathological state. Now, IL-10, not only functions as a suppressor of neuroinflammatory and immuno-proliferative response, but also reduces the synthesis and expression of pro-inflammatory cytokines (IL-12, IL-18, and TNF $\alpha$, etc.) that plays an important role in inflammation, cell death and inhibition of their receptor activation. On the contrary, TNF $\alpha$ expression profile is of pro-inflammatory characteristics thus, it functions as a promoter of the pathological initiators leading to the disease [4]. Both the receptor types have their own signalling pathways distinguished by an intracellular death domain (DD), that is contained by TNFR1 (Tumour necrosis factor receptor 1) while being absent in TNFR2. The latter aids in the promotion of cell survival and proliferation functions whereas, the former (TNFR1) functions in a pro-apoptotic manner. As we move from neuroinflammatory processes to the Reactive Oxygen Species (ROS) generation, one of the most prominent and distinct features associated with NDDs is the reduced rate of production and transportation of the neurotransmitter acetylcholine (Ach) in the diseased subjects. This neurotransmitter is utilized by most of the cholinergic nerve cells and plays a vital role in peripheral and central nervous 
system (PNS and CNS). The loss of cholinergic neurons due to neuronal cell death in response to neural inflammation or high ROS environment is observed in several NDDs including PD (Parkinson's Disease), HD (Huntington Disease), ALS (Amyotrophic Lateral Sclerosis) and AD (Alzheimer's Disease) where a significant decrease in the activity of ChAT (Choline acetyltransferase) is observed [5]. The cholinergic synapses are severely affected by $\mathrm{A} \beta$, correlated to the cognitive decline of the diseased subjects. Further, the biochemical mechanism of Tau $(\tau)$ protein is regulated by several levels of its phosphorylation in the brain. Neuronal cell death mediated by Tau along with hyper phosphorylation also requires the activation of glycogen synthase kinase $3 \beta$ (GSK3- $\beta$ ), observed in Tau pathology where formation of neurofibrillary tangles (NFTs) takes place. Unchecked spreads of these NFTs to several regions of the brain initiates the pathogenesis wherein cognition of the patients is impaired in the first two stages.

Moreover, the activation of GSK3- $\beta$ takes place due to elevated oxidative stress levels, neuroinflammation and apoptotic cell death that is brought about by hyper phosphorylated Tau. Along with neuronal death and hyper phosphorylation in Tau, GSK3- $\beta$ overexpression has been found to cause a failure in mice to perform cognitive functioning [6]. Apart from the current drugs and synthetic compounds designed as essential therapeutics for the treatment of various NDDs, well established phytocompounds are also reported as viable options to improve neural networking and overall well-being of CNS. They have been extensively studied for their anti-inflammatory pursuits, preventing and reducing cellular injuries due to the oxidative stress, modulating multiple signal transduction pathways through indirect and direct effects on enzymes, such as kinases, regulatory proteins and receptors etc. Additionally, it has been suggested that many polyphenols exert their beneficial biological effects through chromatin remodelling and epigenetic adjustments [7]. This broad array of medicinal or biological actions have made phytocompounds a suitable candidate for treating multifactorial disorders. Therefore, to address similar concerns, CGA, a known biologically active polyphenolic compound, derived from the green coffee beans, specifically Coffea Arabica, the richest source of CGA, was opted to study for its therapeutic attributes associated with NDDs [8]. Biosynthesis of CGA occurs as a component of phenolic secondary metabolites of distinct plant species and formed as an ester of cinnamic, quinic and caffeic acid [9]. Further, CGA is reported in many studies to possess enormous anti-inflammatory, antioxidative, neurotrophic, anticancer, antiapoptotic and neuroprotective properties. Also, it exhibits the activation of Akt and ERK1/2 signalling pathways and attenuation of astrocyte activation as reported by Singh et al., 2020 [10] [11]. Nevertheless, its physicochemical property does not show thermodynamic stability as it is very sensitive to degradation and metabolizes to inactive derivatives in circulation with bioavailability of only $33 \%$ in humans [12] [13]. After analysing its pharmaceutical limitations, there arises a primary concern that necessitates the urge to encapsulate CGA in suitable nano carrier system to attain its higher bioavailability, stability and retention time at the targeted site [14]. 


\section{In-Silico Validation by Molecular Docking}

Contemporary advancements in the field of computational biology has opened several new avenues regarding drug development as well as targeted delivery of potential therapeutic compounds. Our research encompasses and explored the various tools that aids in computational simulations at semi-quantum level that enabled us to illustrate and identify distinct molecules involved in NDD pathways leading to the progression of several neurodegenerative pathologies such as over-expressing proteins, mitochondrial damage, neuronal inflammation, amyloid beta plaque formation and elevated ROS levels. Active site molecular docking was conducted at the search volume greater than $27,000 \AA^{3}$ to reveal the binding affinities and structural conformations of the ligand-receptor interaction of CGA (ligand) and multiple protein targets IL-10, TNF-u, Tau protein, Acetylcholine and GSK3 $\beta$ (receptor) [15].

\subsection{Protein Preparation and Active Site Identification}

Procurement and refinement of target protein (receptor) is a vital as well as necessary step towards achieving quality in-silico study results. All the three-dimensional X-ray diffracted crystal structures of the proteins were procured by accessing the Protein Data Bank (PDB) from https://www.rcsb.org/ in .pdb file format. These are all the protein with their associated PDB IDs; IL-10 (PDB ID: 2ILK; https://www.rcsb.org/structure/2ILK), TNF- $\alpha$ (PDB ID: 1TNF; https://www.rcsb.org/structure/1TNF), Tau protein (PDB ID: 6NK4; https://www.rcsb.org/3d-view/6NK4), Acetylcholine (PDB ID: 1OED; https://www.rcsb.org/structure/1oed) and GSK3 $\beta$ (PDB ID: 1H8F; https://www.rcsb.org/structure/1H8F). These .pdb files were then subjected for determining the active sites for ligand binding on them using the CASTp 3.0 (http://sts.bioe.uic.edu/castp/index.html?3trg) tool that provided the explicit position of residues on protein chain. These attained pocket IDs were downloaded and viewed in UCSF Chimera 1.14 to access the complete tomography of the proteins [15] [16]. Thereafter, these downloaded .pdb files were cleansed by removing the water molecules, heat atoms, excising alternating conformations, inserting Kollman charges and adding polar hydrogen to the 3-D protein moiety using Python Molecular Viewer-1.5.6. Subsequently, the .pdb file was converted into .pdbqt file for grid formation.

\subsection{Devising Ligand (CGA)}

Thereafter, the three-dimensional structures for the ligand were retrieved from PubChem database. Chlorogenic acid (3-(3,4-Dihydroxycinnamoyl)quinic acid) having the molecular formula of $\mathrm{C}_{16} \mathrm{H}_{18} \mathrm{O}_{9}$, molecular weight of $354.31 \mathrm{~g} / \mathrm{mol}$. and PubChem ID (CID: 1794427; https://pubchem.ncbi.nlm.nih.gov/compound/Chlorogenic-acid). Ligand was procured in .sdf file format and was processed via LigPrep Tool in Maestro 2015; moreover by employing OPLS3 force field algorithm a minimised 
energy ligand's moiety was obtained via PyRx software and the processed file is then converted to .pdbqt for active site molecular docking [16].

\subsection{Grid Generation and Active Site Molecular Docking Studies}

The grid generation is simply an explicit demarcation of a receptor region where active binding interaction can occur which was performed by using AutoDockTools-1.5.6. Also to identify the potential active binding sites and other associated data related to interacting residues CASTp 3.0

(http://sts.bioe.uic.edu/castp/index.html?3trg) was employed which further facilitates active site molecular docking [17]. AutoDock Vina was used to carry out molecular docking to investigate the receptor-ligand interaction. All the processed .pdbqt files of receptor and ligand were employed and this process was repeated for all five targeted proteins separately. The Lamarckian Genetic Algorithm (LGA) was implemented to understand and analyse various aspects of flexible docking and PMF (Performance Management Framework) score [18]. Active site molecular docking was concluded after the determination of the best binding affinities along with their associated three-dimensional structural conformations at their respective lowest energy levels. Docked file was then subsequently processed to make the .pdb complex of the ligand-receptor file for visualization by PyMOL Viewer 4.3.0 and Discovery Studio 2020 Client. For an elaborate and comprehensive docking and visual analysis UCSF Chimera 1.14 and LIGPLOT $^{+}$v.2.1 were employed [19].

\section{Materials and Methodology}

\subsection{Materials}

Chlorogenic acid (CGA) (RM2705) was purchased from HI Media Laboratories, Mumbai, India. Polycaprolactone (PCL), Chitosan (CS) and Dialysis membrane were procured from Sigma-Aldrich (USA). All the other chemicals employed in experiments were also of analytical grade.

\subsection{Methodology}

\subsubsection{Quantitative Analysis of Chlorogenic Acid (CGA)}

The quantitative estimation of CGA was performed by preparing the standard stock solution of CGA $(100 \mu \mathrm{l} / \mathrm{mL})$ with subsequent dilutions (10 - 100 $\mu \mathrm{l} / \mathrm{mL}$ ) in ethanol. The $\mathrm{R}^{2}$ value of 0.992 was recorded after taking the $\mathrm{ab}$ sorbance for the prepared samples at $334 \mathrm{~nm}$. This prepared standard graph was later used for estimating the CGA concentrations in various analytical assays [20].

\subsubsection{Synthesis of CGA Loaded Nanoparticles (CGA-NPs)}

Fabrication of CGA-NPs was done through ionic gelation method (Figure 1(a)). For this, CS and PCL were prepared separately in $3 \%$ glacial acetic acid by homogenizing them overnight and thereafter, keeping the same at $37^{\circ} \mathrm{C}$ separately. 


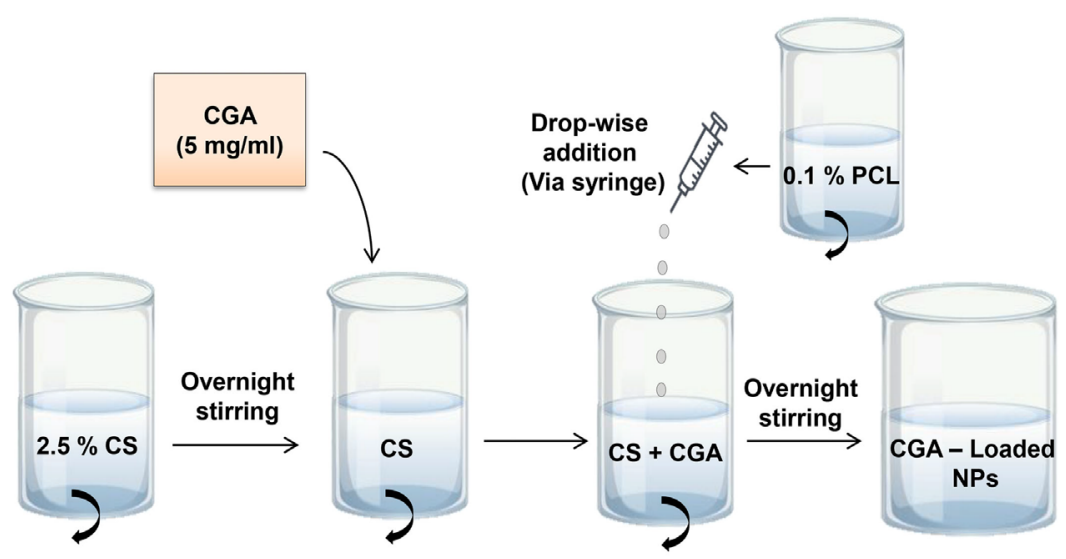

(a)

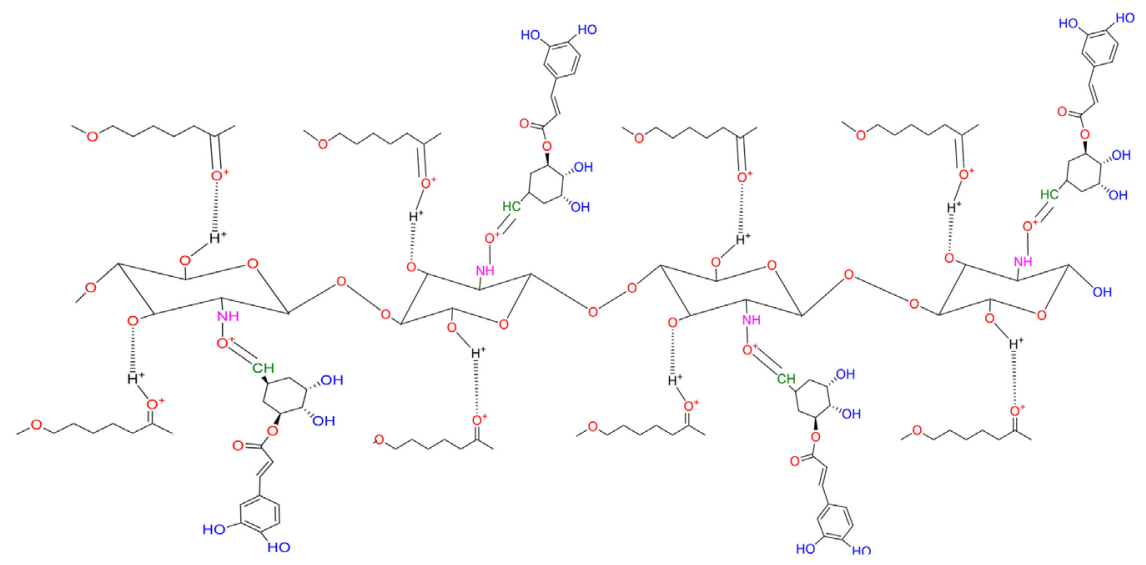

(b)

Figure 1. (a) Diagrammatic representation showing the step by step synthesis of CGA-NPs by ionic gelation method; (b) Adaptation of probable lattice formation between CS and PCL with CGA embedded in it.

Further, CGA $(5 \mathrm{mg} / \mathrm{mL})$ was added in varied concentration of CS solution $(1.5 \%-2.5 \%, \mathrm{w} / \mathrm{v})$ and this solution was blended with PCL solution of different concentrations $(0.1 \%-0.3 \%)$ drop wise using a syringe dropper to ensure calibrated rate of addition. Lastly, the homogenised solution was stirred continuously for overnight and covered with sieve for solvent evaporation [21] [22]. Thus Figure 1(b) presents the possible lattice structure between CS, CGA and PCL.

\subsubsection{Determination of Encapsulation Efficiency (EE)}

CGA encapsulated inside the polymer matrix was centrifuged $(11,200 \mathrm{~g})$ for 20 min at $37^{\circ} \mathrm{C}$ and the supernatant was collected subsequently. This step was repeated thrice, and the pellet was dissolved in distilled water along with collection of the respective supernatant [23]. Absorbance of the supernatant was recorded at $334 \mathrm{~nm}$ and the concentration of drug in their respective supernatant was extrapolated using the standard calibrated curve [24]. To determine the total amount of drug suspending in supernatant, the EE was calculated using the 
mathematical expression given below:

$$
\text { Encapsulation Efficiency }(\mathrm{EE})=\frac{D_{t}-D_{s}}{D_{t}}
$$

where, $D_{t}$ and $D_{s}$ refer to the total amount of drug and total amount of drug present in supernatant respectively [25].

\subsubsection{Statistical Optimization of CGA-NPs}

The experimental design was laid down for optimising the various formulation batches by Box Behnken design to compose polynomial model for CGA-NPs optimisation process [26]. Four independent (CS, PCL concentration, rate of addition and sonication time) and one dependent (EE) variables were selected for optimization using Design Expert (Version-12, Stat-Ease Inc., Minneapolis, Minnesota) [27] [28]. The design description is listed in Table 1 and the polynomial equation generated through quadratic process order on the basis of the experimental design set up is as follows:

$$
\begin{aligned}
\mathrm{EE}= & Y+X_{1} A-X_{2} B-X_{3} C-X_{4} D-X_{5} A B-X_{6} A C+X_{7} A D-X_{8} B C \\
& -X_{9} B D-X_{10} C D+X_{11} A^{2}-X_{12} B^{2}-X_{13} C^{2}-X_{14} D^{2}
\end{aligned}
$$

where, $\mathrm{EE}$ is the evaluated response of the independent variables, i.e.; $\mathrm{EE}, Y$ (59.4) is the intercept and $X_{1}-X_{14}$ are the regression coefficients that were calculated from the experimental data set values of EE [29] [30]. $A, B, C$ and $D$ are the codes for all the independent variables which depict the interactions whereas $A^{2}$, $B^{2}, C^{2}$ and $D^{2}$ represents the quadratic terms [31].

\begin{tabular}{|c|c|c|c|}
\hline \multirow{2}{*}{ Independent Variable } & \multicolumn{3}{|c|}{ Levels } \\
\hline & -1 & 0 & 1 \\
\hline $\begin{array}{c}\mathrm{A}=\text { Polymer } 1 \\
\mathrm{CS} \text { concentration }(\mathrm{w} / \mathrm{v})\end{array}$ & 1.5 & 2 & 2.5 \\
\hline $\begin{array}{c}\mathrm{B}=\text { Polymer } 2 \\
\text { PCL concentration }(w / v)\end{array}$ & 0.1 & 0.2 & 0.3 \\
\hline $\mathrm{C}=$ Sonication Time $(\min )$ & 10 & 15 & 20 \\
\hline $\mathrm{D}=$ Rate of Addition (min) & 10 & 20 & 30 \\
\hline Dependent Variable & \multicolumn{3}{|c|}{ Constraint } \\
\hline $\mathrm{EE}=$ Encapsulation Efficiency (\%) & \multicolumn{3}{|c|}{ Maximum } \\
\hline
\end{tabular}

Table 1. Description of various independent and dependent variables taken in optimisation process of CGA-NPs by Box-Behnken design.

\subsection{Characterization of Formulated CGA-NPs}

\subsubsection{Particle Size Analysis (PSA) and Zeta Potential (ZP)}

PSA evaluates the size of particles in the colloidal solution that is based on scattering of light, subjected to the random thermal Brownian motion thus, it is also named as Dynamic light scattering (DLS) [32] [33]. ZP is a measure of a charge on the surface of NPs and is measured on the Malvern Zetasizer Nano ZS (3000 HS) and it is conceptually based on the technique of electrophoretic light scattering where particle motion is detected in an applied electric field [34] [35]. 
Test samples for both the analysis methods were prepared by diluting them with distilled water in the ratio of 1:100 followed by ultra-sonication $(11,200 \mathrm{~g})$ for 20 min and subjected for Zeta sizer unit analysis [36].

\subsubsection{Transmission Electron Microscopy (TEM)}

In Transmission electron microscopy, the electron beam scans the surface of the sample to give a 2-dimensional image and operates it at a much smaller wavelength when compared to standard light microscope. Therefore, the limiting resolution of electron microscope is much higher thus, enables it to provide better optical resolution [37]. The morphology of the NPs was characterized by TEM using TECHNAI $200 \mathrm{kv}$ TEM (Fei, Electron Optics). The optimised CGA-NPs were 100 times diluted (1:100) in 5\% acetic acid and were sonicated for $15 \mathrm{~min}$. Subsequently they were coated with $2 \%$ Phosphotungstic acid (PTA), a dye that helps in fixing the sample and a drop from the prepared sample was fixed on the carbon coated copper grid [38].

\subsubsection{Fourier Transform Infrared Spectroscopy (FT-IR)}

Fourier-transform infrared spectroscopy (FT-IR) was done to identify and evaluate various molecular constituents present on the surface of the nano formulation using IR-810, JASCO, Tokyo at Punjab University, Chandigarh, Punjab, India. The technique involves transmission of infrared radiation across the sample due to which different components absorb or emit radiation across different wavelengths of the infrared spectrum [39]. The test samples (CGA, only NPs and CGA-NPs) were prepared by Potassium Bromide ( $\mathrm{KBr}$ ) disc method and the prepared $\mathrm{KBr}$ pellets were then placed in the desiccator to form a fine thin film, that is placed inside the grid for analysis. The FT-IR spectrum is scanned from $400-4000 \mathrm{~cm}^{-1}$ band width to identify the functional groups present on the surface of the samples [40].

\subsection{Physiochemical Parameters (pH, Conductivity, Density, Specific Gravity and Viscosity)}

Physiochemical parameters of formulated NPs were assessed to explore the specific behaviour of NPs in the colloidal solution. Evaluation of such parameters is necessary to determine the effective permeation of the designed NP-formulation through biological barriers [41]. The $p \mathrm{H}$ of prepared CGA formulations was measured by preparing $1 \%$ aqueous solution of the same and measuring it by using a calibrated digital $p \mathrm{H}$ meter (Mettler Toledo MP 220, Greifensee, Switzerland) at $37^{\circ} \mathrm{C}$. Thereafter, conductivity of CGA-NPs was evaluated on electrical conductivity metre (Orion Star A212) at $25^{\circ} \mathrm{C}$. Conductivity is defined as the degree of dissolved ions in the dispersed phase relative to the dispersion phase. Furthermore, density and specific gravity of the CGA-NPs were measured using E-Z Red SP101 Battery Hydrometer and specific gravity bottle respectively. Specific gravity describes the internal friction to flow. Lastly, viscosity was measured using viscometer (Brookfield viscometer) which is a measure of a fluid's resistance to flow [42]. 


\subsection{In-Vitro Release Kinetics}

The release kinetics of a compound is affected by various factors like $\mathrm{pH}$, salt concentration and temperature that necessitates the evaluation of the release pattern of compound from the nano formulation. CGA-NPs were dispersed in 2 $\mathrm{mL}$ of distilled water and placed in donor compartment [43]. The receiver compartment was filled with phosphate buffer $(20 \mathrm{~mL}, \mathrm{pH} 7.2)$ and in between both the compartments pre-treated dialysis membrane was placed to establish the concentration gradient. Thereafter, setup was kept on the magnetic stirrer and sample from the outlet port was withdrawn after every hour followed by equal replacement of PBS to maintain equilibrium [44]. The absorbance of collected samples from the receiver port was analysed at $334 \mathrm{~nm}$ and Cumulative Drug Release (CDR \%) was estimated by the following expression:

$$
\operatorname{CDR}(\%)=\frac{\text { Volume of sample withdrawn }}{P[t-1]+P[t]} \times 100
$$

where, $P[t]$ refers to the percentage release at time $[t]$ and $P[t-1]$ is the percentage release at time $[t-1]$. The prediction of compound release pattern for CGA from the CGA-NPs was performed by fitting CDR into various release kinetic models [45] by evaluating the characteristic equation and $\mathrm{R}^{2}$ value and best fit is analysed [46].

Data Analysis: All set of experimental data are reported as mean \pm SD and the validation of datasets were done by using two-way ANOVA with $\mathrm{p}$ value < 0.01 .

\section{Results and Discussion}

\subsection{In-Silico Validation of Receptor-Ligand Interaction}

As discussed earlier, in-silico studies were performed by AutoDock Vina ( $\mathrm{v}$ 1.5.6) that helped in analysing the ligand interaction at specific site with all the five-protein-complex structures resulting in the effective binding affinity expressed in terms of $\mathrm{kcal} / \mathrm{mol}$. Interaction between proteins and CGA involves binding of various amino acid residues which results in a formation of highly stable complex. This stable complex formed between the target and ligand shows the blocked active site of the over-expressing proteins which is predicted to decrease the ROS production and later preventing neurological imbalances [47].

\subsection{D Structural Conformation of Proteins and Ligand}

Three-dimensional conformations with potential active binding sites of all five target proteins (receptor) are illustrated in Figures 2(a)-(e). These Figures elucidates the precise positioning of the amino acid residues in the protein structure and are labelled with distinct colour-coded regions on protein surface along with their active site binding pockets (shown with red boxes) which are classed as specific regions exhibiting higher binding affinity for their respective ligands. 


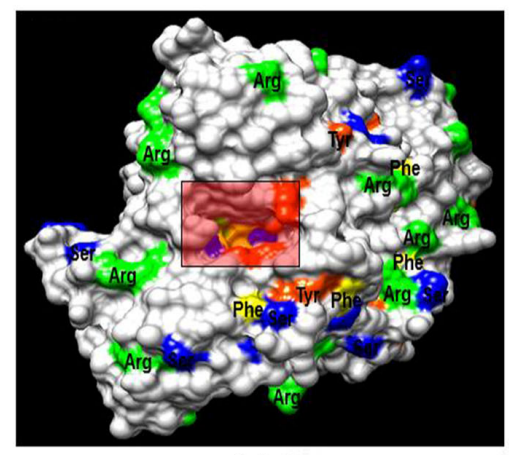

(a)

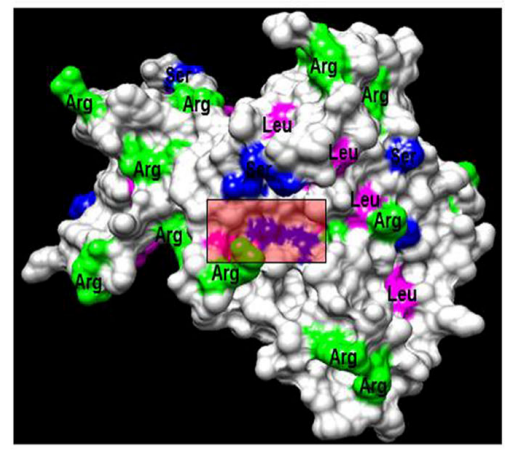

(b)

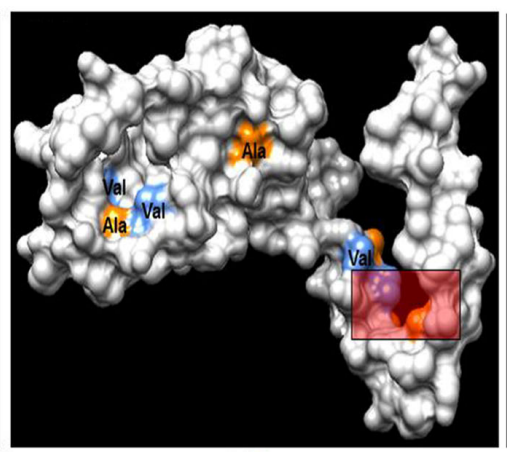

(c)

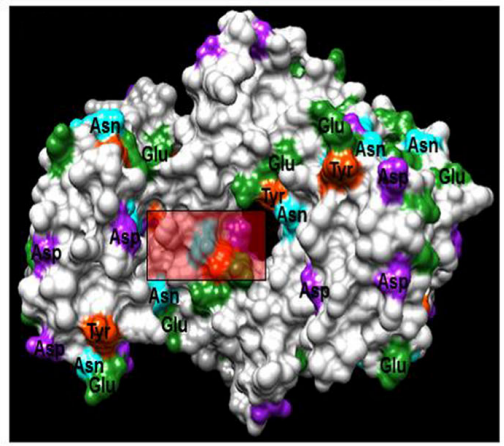

(d)

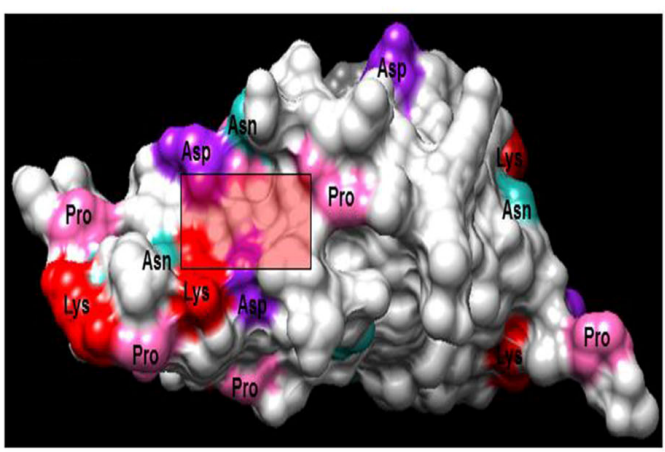

(e)

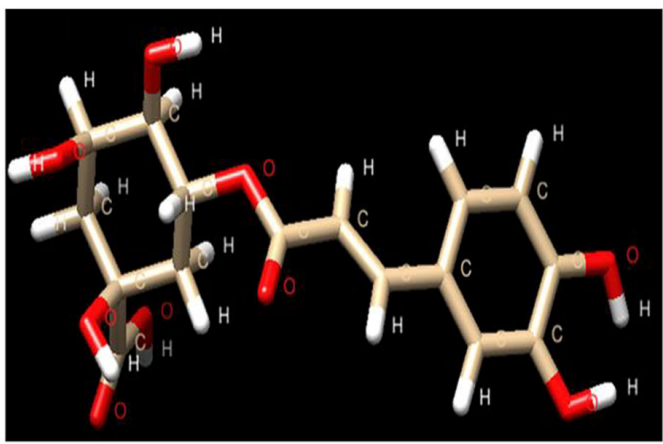

(f)

Figure 2. ((a)-(e)) 3D structure of all five-protein-complex with the active site prediction with interacting residues; (a) Acetylcholine; (b) GSK3- $\beta$; (c) IL-10; (d) Tau; (e) TNF- $\alpha$; (f) Image representing the 3D structure of CGA using chimera 1.14.

Similarly, Figure 2(f) shows the structure of ligand (CGA) with its carboxyl, hydroxyl and ester groups placement in its chemical structure [48]. CGA showed an average weight of $354.30 \mathrm{mM}$, topological polar surface area of $165 \mathrm{a}^{2}$, formal charge of 0 and covalently-bounded unit count of 1 , which was retrieved from its PubChem database [49].

\subsection{Receptor-Ligand Interaction}

The protein-ligand interaction as demonstrated in the study explains the binding profile of the ligand within the active binding pocket of protein resolutely by hydrogen bonding through pi-pi hydrophobic interactions as shown in Figure 3. The essential factor responsible for an ideal binding of ligand with the active binding site pockets is directly related with its position and alignment of the substituents on the molecular surface. The docking was performed with all the five proteins; however, the most active protein-ligand interaction was reported in acetylcholine and GSK- $3 \beta$. From Table 2 it can be deduced that acetylcholine exhibits the best binding affinity than rest of the proteins. Its interaction with CGA showcases 6 hydrogen bonds between hydroxyl, carbonyl and nitric group of ligand (CGA) with the residues [Ser 125, Ser 293, Tyr 124, Tyr 337, Arg 296, Phe 295] therefore possessing an excellent binding energy of $-9.3 \mathrm{kcal} / \mathrm{mol}$ [50]. Several hydrophobic interactions were also identified with specific residues [Phe 297, Phe 338, Val 294, Leu 289, Thr 83, Asp 74, Asn 87, Gly 121, Trp 86, His 447] 


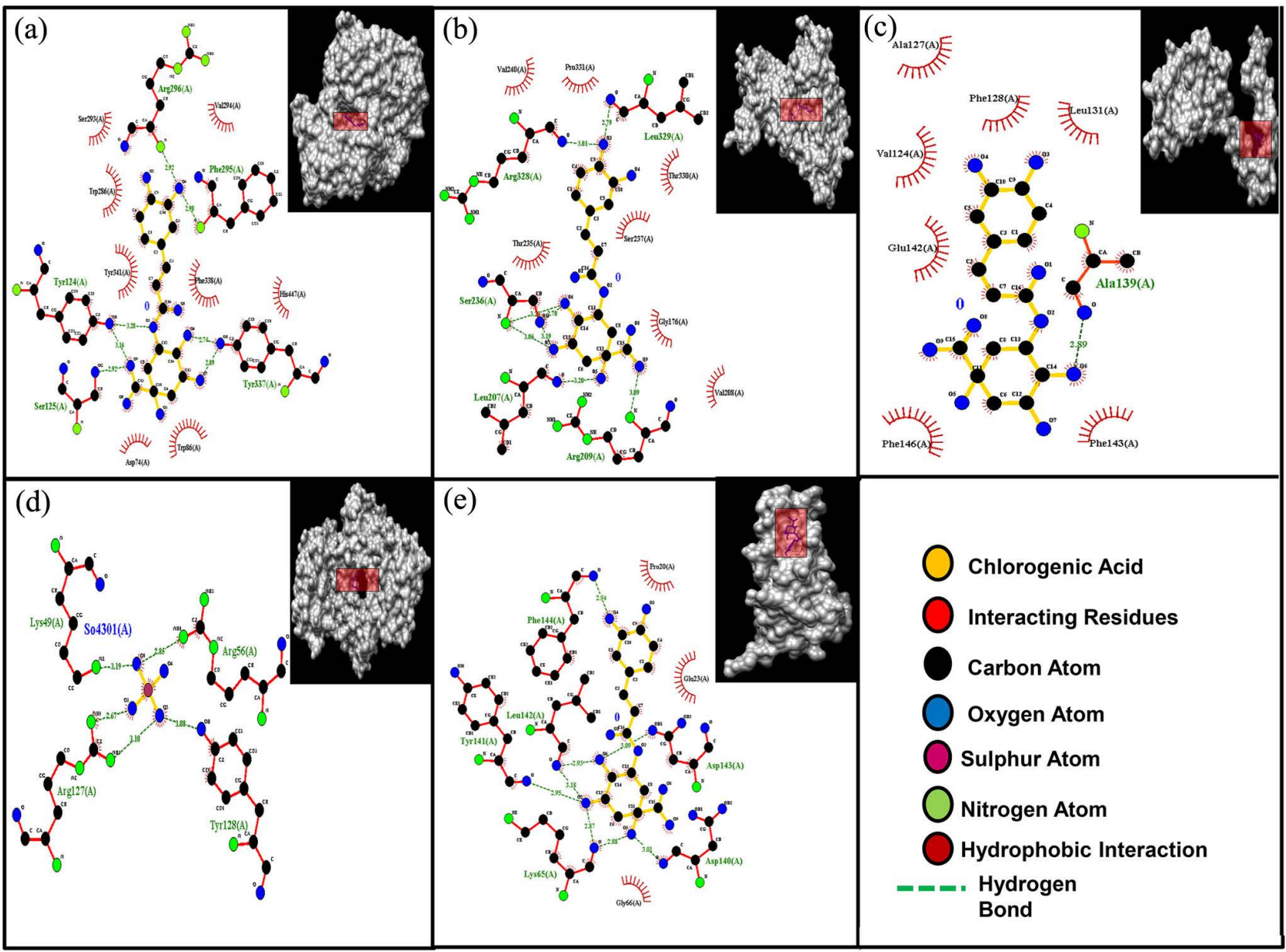

Figure 3. Receptor-ligand interactions at the active binding site with their respective LigPlot. (a) Acetylcholine; (b) GSK3- $\beta$; (c) IL-10; (d) Tau Protein; (e) TNF $\alpha$.

Table 2. Receptor-ligand interaction in terms of binding affinity.

\begin{tabular}{|c|c|c|c|c|c|}
\hline \multirow{2}{*}{ Protein } & & \multirow{2}{*}{$\begin{array}{l}\text { Binding } \\
\text { Affinity } \\
(\mathrm{kcal} / \mathrm{mol})\end{array}$} & \multicolumn{3}{|c|}{ Interacting Residues } \\
\hline & & & Hydrogen Residues & Hydrophobic Residues & Salt Bridges (No.) \\
\hline Acetylcholine & & -9.3 & $\begin{array}{l}\text { Ser }(125,293), \\
\text { Tyr }(124,337) \\
\text { Arg } 296, \text { Phe } 295\end{array}$ & $\begin{array}{l}\text { Phe }(297,338), \text { Val } 294, \\
\text { Leu } 289, \text { Thr } 83, \text { Asp } 74, \text { Asn } 87 \text {, } \\
\text { Gly } 121, \operatorname{Trp} 86, \text { His } 447\end{array}$ & $\begin{array}{l}\text { Arg } 296(1) \\
\text { Phe } 295(1)\end{array}$ \\
\hline GSK- $3 \beta$ & $\begin{array}{l}\text { Chlorogenic } \\
\text { Acid }\end{array}$ & -6.9 & $\begin{array}{c}\text { Ser } 236, \\
\text { Leu }(207,329) \\
\quad \operatorname{Arg} 328\end{array}$ & $\begin{array}{c}\text { Arg } 209, \text { Val }(208,240), \text { Gly } 176 \\
\text { Thr }(235,330,326), \text { Ser }(174,237) \\
\text { Pro }(326,331), \text { His } 173\end{array}$ & $\begin{array}{l}\operatorname{Arg} 209(1) \\
\text { Ser } 236(2)\end{array}$ \\
\hline IL-10 & & -6.1 & $\begin{array}{l}\text { Val } 124, \\
\text { Ala } 139\end{array}$ & $\begin{array}{l}\text { Phe }(128,146) \text {, Ile } 145 \text {, Glu 142, } \\
\text { Ala 127, Leu 131, Lys 138, Met } 140\end{array}$ & - \\
\hline Tau Protein & & -6.8 & $\begin{array}{c}\text { Tyr 19, Asn 50, } \\
\text { Asp 20, Glu 89, Lys } 49\end{array}$ & $\begin{array}{c}\text { Asp }(20,21,51), \text { Lys } 85 \\
\text { Arg }(18,55), \text { Gly } 54, \text { Glu 17, Val } 51\end{array}$ & $\begin{array}{l}\text { Lys } 49(1) \text {, } \\
\text { Arg } 56(1) \text {, } \\
\text { Arg } 127(2)\end{array}$ \\
\hline $\mathrm{TNF} \alpha$ & & -6.5 & $\begin{array}{c}\text { Asp }(140,143), \\
\text { Lys } 65 \text {, Pro } 20 \text {, Gly } 66\end{array}$ & $\begin{array}{l}\text { Phe } 144 \text {, Ala 145, Glu 23, Pro 139, } \\
\text { Gly }(24,66) \text {, Gln 67, Tyr 141, Leu } 142\end{array}$ & - \\
\hline
\end{tabular}


contributing to the primary binding interaction. The salt bridge formation, at position Arg 296 and Phe 295 was also observed between the oxygen and nitrogen atoms which makes the structure more stable and reinforces the interaction at the active site cavity. Thereafter, GSK- $3 \beta$ was another protein with higher docking pose, forming 4 [Ser 236, Leu 207, Leu 329, Arg 328] hydrogen bonds with binding efficiency comparatively less than that of Acetylcholine ( $-6.9 \mathrm{kcal} / \mathrm{mol})$ [51]. The hydrophobic interacting residues [Phe 297, Phe 338, Val 294, Leu 289, Thr 83, Asp 74, Asn 87, Gly 121, Trp 86, His 447] and showed the salt bridge formation at Arg 209 and Ser 236. Similarly, the results were prepared for the other ranked targets revealing their hydrogen bond interactions to fix ligand firmly and tightly at the targeted site. It is clearly evident from the Table 2 that each target has a significant binding energy ranging from $-9.3 \mathrm{kcal} / \mathrm{mol}$ to $-6.5 \mathrm{kcal} / \mathrm{mol}$ pointing towards the fact that the CGA has an exemplary binding capability towards all the retrieved targets for limiting process of neurodegeneration in $\mathrm{AD}$ cases [52].

\subsection{Statistical Optimization}

After subjecting the prepared design model for statistical analysis by Box-Behnken method, 29 runs with p value of 0.0003 for the model system were obtained. Also, the effect of independent variables over dependent ones was further studied and contour plots for the same were developed. The concentration of polymers (CS and PCL), rate of addition and sonication time have a pivotal role on the EE of the compound (CGA) inside the lattice structure. Also, these factors further act as an important parameter in altering or controlling the release kinetics of CGA from the matrix system [53]. The resultant effect of independent variables on the $\mathrm{EE}$ can be explained by the following equation:

$$
\begin{aligned}
\mathrm{EE}= & 59.4+17.8442 A-4.36583 B-16.2083 C-4.48667 D-6.3225 A B \\
& -4.9 A C+1.04 A D-0.1 B C-0.325 B D-2.175 C D+14.6858 A^{2} \\
& -5.43167 B^{2}-11.7429 C^{2}-3.00042 D^{2}
\end{aligned}
$$

where, $A$ is CS concentration $(\mathrm{mg} / \mathrm{mL}), B$ is PCL concentration $(\mathrm{mg} / \mathrm{mL}), C$ is the sonication time and $D$ is the rate of addition. Moreover, on the basis of resultant data set as represented in Table 3, the concentration of $2.5 \%$ CS and $0.1 \%$ PCL with $10 \mathrm{mg} / \mathrm{mL}$ of CGA (Run 18) was selected as the optimised formulation set as it exhibited the highest and most efficient EE value of $99.59 \%$ and also corresponded well with plotted RSM model graphs (Figure 4) with $\mathrm{p}<$ $0.05(0.05 \leq \mathrm{p} \leq 0.1)$ as represented in Table 3 [54]. The maximum EE was found to be $99.59 \%$ with $2.5 \%$ of CS and $0.1 \%$ of PCL [55].

The developed model system was found to be highly significant with $\mathrm{R}^{2}$ value of 0.8819 and F-value of 7.47 [56]. After the analysis of polynomial equation data, it was inferred that combination ratio of factor A (CS concentration) and factor C (sonication time) are directly proportional to the concentration of compound encapsulated. Whereas, factor B (PCL concentration) and factor D (rate of addition) were not directly impacting the process of encapsulation (Table 4) [57] [58]. 
Table 3. Representing the generated p-value score in correlation with EE amongst all runs.

\begin{tabular}{cccccccccccccccc}
\hline & Intercept & $\mathrm{A}$ & $\mathrm{B}$ & $\mathrm{C}$ & $\mathrm{D}$ & $\mathrm{AB}$ & $\mathrm{AC}$ & $\mathrm{AD}$ & $\mathrm{BC}$ & $\mathrm{BD}$ & $\mathrm{CD}$ & $\mathrm{A}^{2}$ & $\mathrm{~B}^{2}$ & $\mathrm{C}^{2}$ & $\mathrm{D}^{2}$ \\
\hline EE & 59.4 & $\mathbf{1 7 . 8 4 4 2}$ & -4.36 & -16.20 & -4.48 & -6.32 & -4.9 & 1.04 & -0.1 & -0.32 & -2.17 & $\mathbf{1 4 . 6 8}$ & -5.43 & -11.74 & -3.004 \\
$\mathrm{p}$-Value & & $<0.0001$ & 0.159 & $<0.0001$ & 0.14 & 0.23 & 0.31 & 0.84 & 0.98 & 0.95 & 0.67 & $\mathbf{0 . 0 0 2 5}$ & 0.19 & 0.01 & 0.46 \\
\hline
\end{tabular}

Table 4. Analysis of variance (ANOVA) for designed quadratic model system.

\begin{tabular}{ccccccc}
\hline Source & Sum of Squares & df & Mean Square & F value & p-value & \\
\hline Model & $10,830.94$ & 14 & 773.64 & 7.47 & 0.0003 & significant \\
A: CS Conc. & 3820.97 & 1 & 3820.97 & 36.90 & $<0.0001$ & \\
B: PCL Conc. & 228.73 & 1 & 228.73 & 2.21 & 0.1594 & \\
C: Sonication Time & 3152.52 & 1 & 3152.52 & 30.44 & $<0.0001$ & \\
D: Rate of Addition & 241.56 & 1 & 241.56 & 2.33 & 0.1490 & \\
AB & 159.90 & 1 & 159.90 & 1.54 & 0.2344 \\
AC & 96.04 & 1 & 96.04 & 0.9274 & 0.3519 \\
AD & 4.33 & 1 & 4.33 & 0.0418 & 0.8410 & \\
BC & 0.0400 & 1 & 0.0400 & 0.0004 & 0.9846 & \\
BD & 0.4225 & 1 & 0.4225 & 0.0041 & 0.9500 & \\
CD & 18.92 & 1 & 18.92 & 0.1827 & 0.6755 & \\
$\mathrm{~A}^{2}$ & 1398.96 & 1 & 1398.96 & 13.51 & 0.0025 & \\
$\mathrm{~B}^{2}$ & 191.37 & 1 & 191.37 & 1.85 & 0.1955 & \\
$\mathrm{C}^{2}$ & 894.46 & 1 & 894.46 & 8.64 & 0.0108 & \\
$\mathrm{D}^{2}$ & 58.39 & 1 & 58.39 & 0.5639 & 0.4651 & \\
& & & & &
\end{tabular}

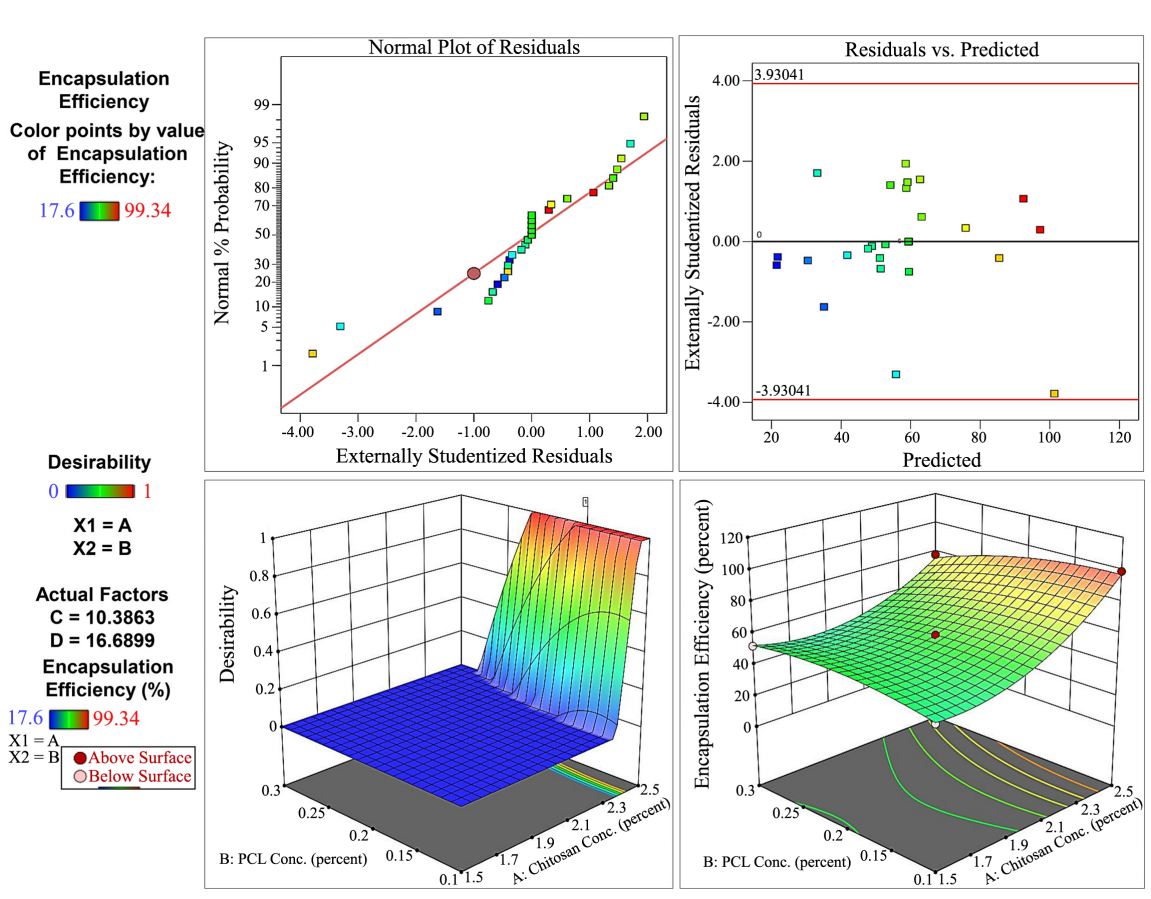

Figure 4. The response surface methodology based graphical plots representing the statistical modelling of CGA-NPs correlating their encapsulation efficiencies with all sets of independent variables. 


\subsection{Particle Size Analysis (PSA) and Zeta Potential (ZP)}

Based on the results of EE, the highest EE yielding nano formulation was selected for PSA and ZP analysis. The average particle size was recorded as 101.9 $\mathrm{nm}$ with polydispersity index (PDI) of 0.066 suggesting the existence of homogeneous colloidal solution (Figure 5(a)) [59]. Further, ZP of CGA-NPs showed to be $-17.4 \mathrm{mV}$ (Figure $5(\mathrm{~b})$ ) implying lower charge profile of the NPs which ensures no possible aggregation and minimal repulsive forces with higher stability of prepared nano formulation [60].

$\begin{array}{rllll} & & \text { Size (r.nm): } & \% \text { intensity } & \text { Width (r.nm): } \\ \text { Z-average (r.nm): } 101.9 & \text { Peak 1: } & 110.4 & 100.0 & 30.80 \\ \text { PdI: } 0.066 & \text { Peak 2: } & 0.000 & 0.0 & 0.000 \\ \text { Intercept: 0.935 } & \text { Peak 3: } & 0.000 & 0.0 & 0.000 \\ \text { Result quality: Good } & & & & \end{array}$

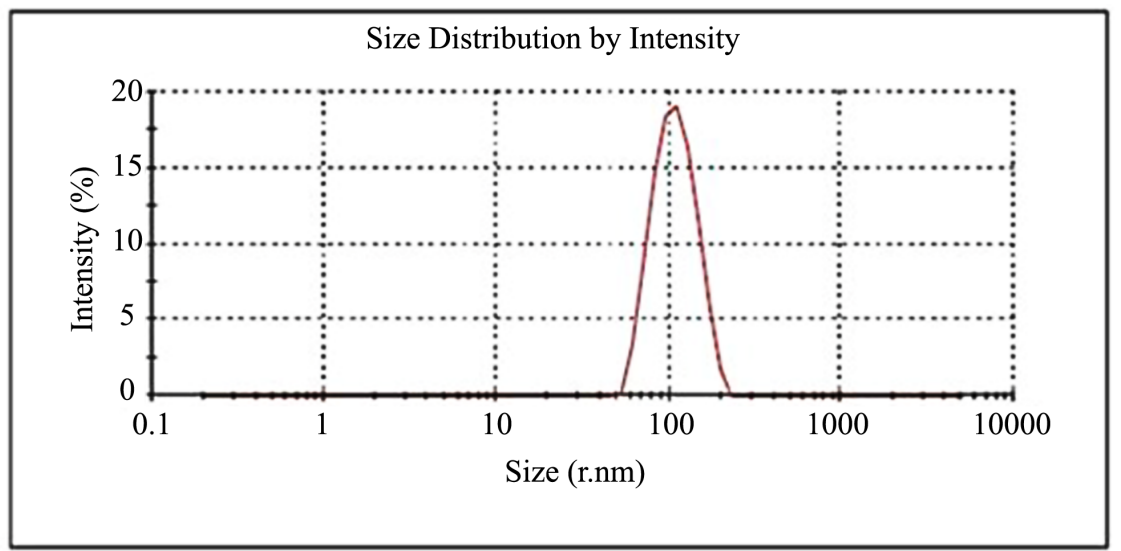

(a)

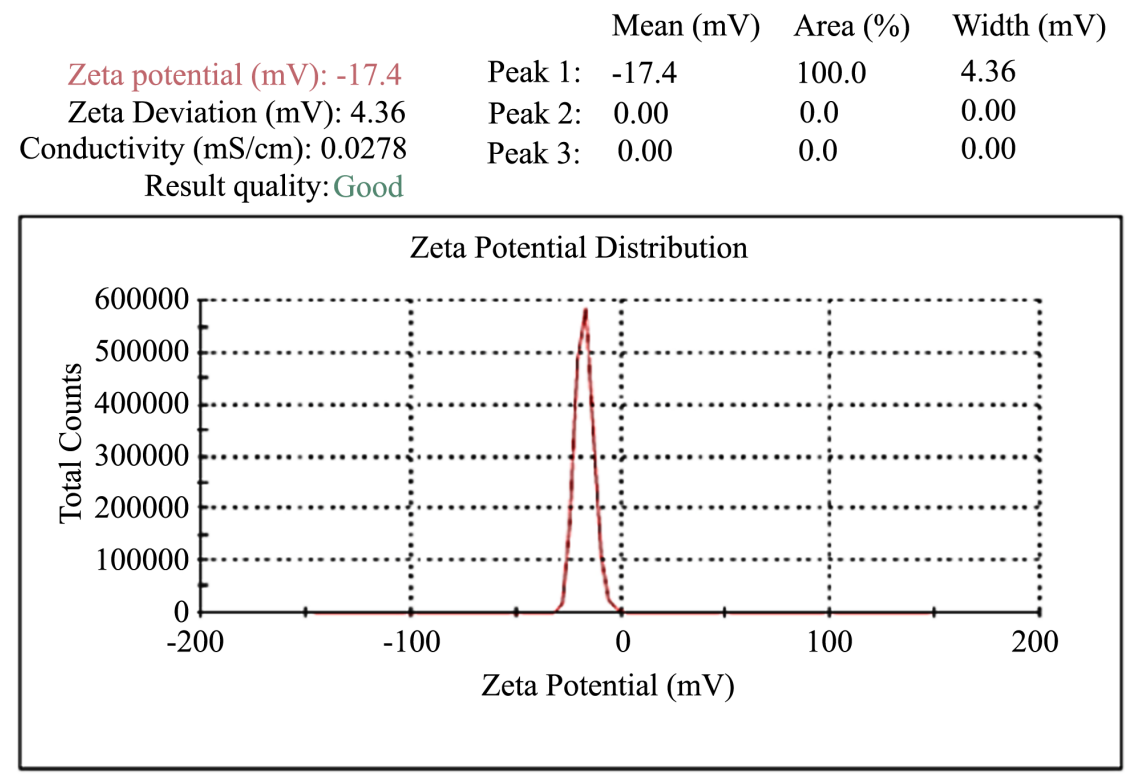

(b)

Figure 5. (a) Graph representing the particle size analysis and (b) Zeta potential of the optimised nanoparticles (CGA-NPs). 


\subsection{Transmission Electron Microscopy (TEM)}

TEM reveals the morphological structure and size of the nanoparticle and the image taken at $15,000 \times$ magnification with the scale of $100 \mathrm{~nm}$ reflected spherical morphology of the NPs with particle size range between 90 - $110 \mathrm{~nm}$ (Figure 6) [61] [62]. This data is in compliance with the previous characterisation data of PSA [63].

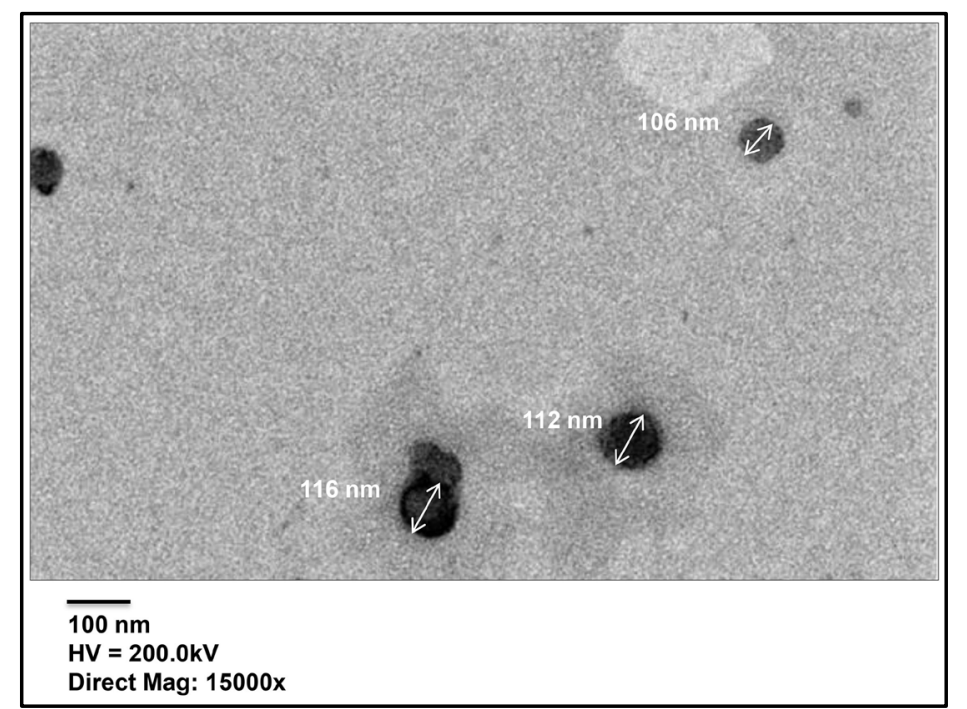

Figure 6. TEM micrographs showing optimised CGA-NPs at $15,000 \times$ at the scale bar of $100 \mathrm{~nm}$.

\subsection{FT-IR Analysis}

FT-IR graph shows the topographical properties and surface phenomenon of the NPs subjected for the analysis (Figure 7). The samples containing NPs were irradiated with infrared light and the functional groups present on the surface of nanoparticles were observed. CGA consists of carboxylic group, hydroxyl group and ketone group [64] [65]. The signature peaks of FT-IR corresponded to O-H stretch, $\mathrm{C}=\mathrm{O}$ stretch of carboxylic acid and $\mathrm{O}-\mathrm{H}$ stretch of hydroxyl group and $\mathrm{C}=\mathrm{O}$ stretch of ketone group at $2345 \mathrm{~cm}^{-1}, 1793 \mathrm{~cm}^{-1}, 3386 \mathrm{~cm}^{-1}$ and $1654 \mathrm{~cm}^{-1}$ respectively [66]. The $\mathrm{O}-\mathrm{H}$ stretch of $\mathrm{COOH}$ group shows a broad and strong peak in the range of $3300-2500 \mathrm{~cm}^{-1}$ whereas, the $\mathrm{C}=\mathrm{O}$ group in the range of $1680-1750 \mathrm{~cm}^{-1}$ depicts increase in wavenumber due to decrease in bond length because of electronegativity concept as represented in Figure 7. The O-H of hydroxyl group in range of $3550-3200 \mathrm{~cm}^{-1}$ was involved in intermolecular bonding with esters whereas, the carbonyl of ketone group in range $1750-1680 \mathrm{~cm}^{-1}$ showed the broad peak due to maximum absorption in strongest IR region [67]. On encapsulation of CGA in CH-PCL matrix a broad peak of PCL and CGA is observed at $3270 \mathrm{~cm}^{-1}$ corresponding to amide functional group. The amide functional group combines the feature of amine and ketone because it has both $\mathrm{N}-\mathrm{H}$ and $\mathrm{C}=\mathrm{O}$ bond. Therefore, amide shows somewhat broad bend at left end of spectrum in range of $3500-3100 \mathrm{~cm}^{-1}-\mathrm{NH}$ stretch [68]. 


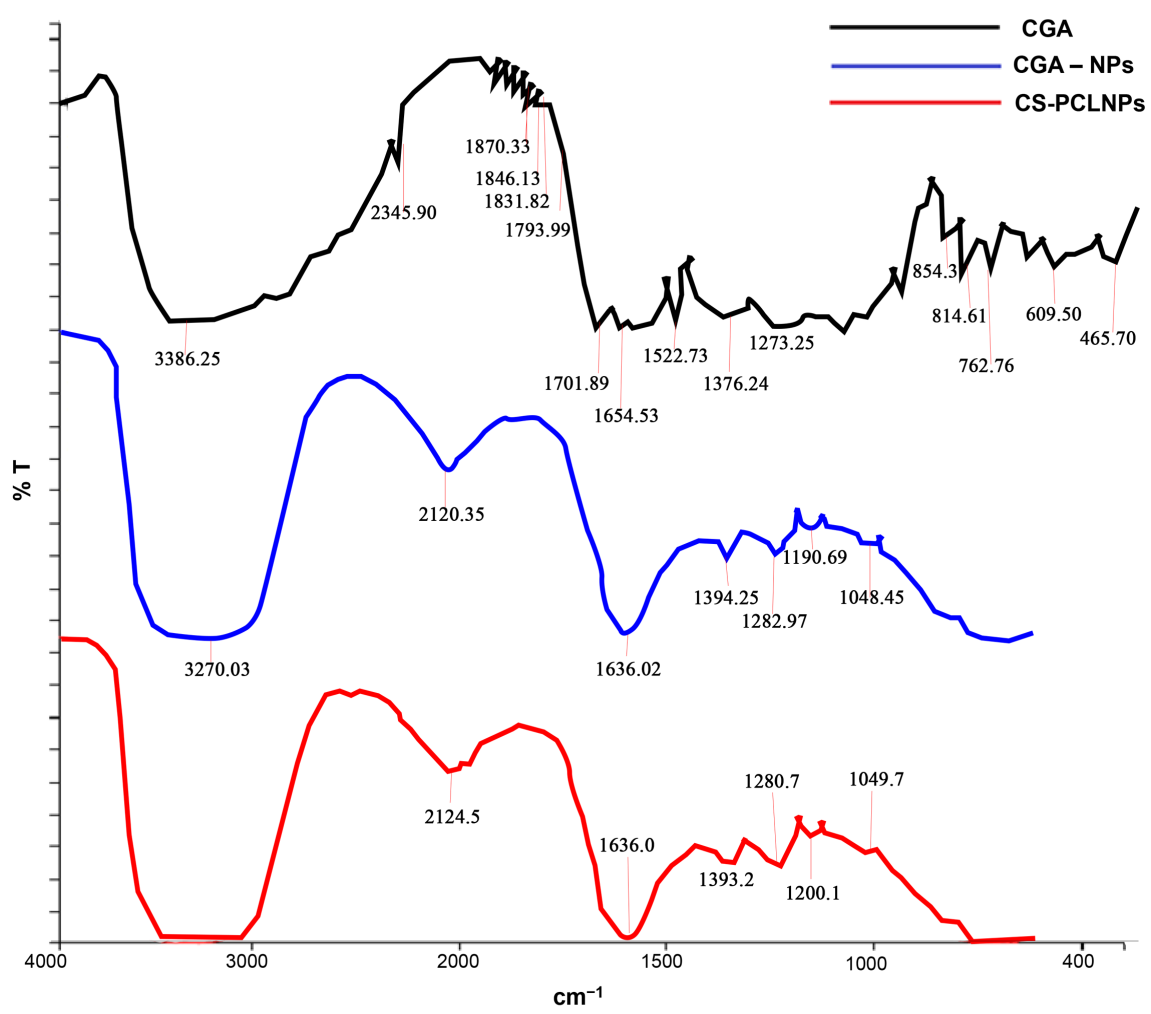

Figure 7. Image exhibiting the FT-IR spectra of all the test samples between the wavelength ranges of $400-4000 \mathrm{~cm}^{-1}$.

\subsection{Physiochemical Parametric Analysis of Formulated Nanoparticles}

CGA-NPs were tested to evaluate several physiochemical parameters as listed in Table 5. Recorded data showed the $p \mathrm{H}$ value of CGA-NPs as $6.7 \pm 0.26$ which is acceptable under the GRAS (generally regarded as safe) limits to ensure safe ionic strength for the nano formulation [69] [70]. Also, conductivity of NPs was observed to be $0.221 \pm 0.05 \mathrm{~S} \cdot \mathrm{m}^{-1}$ that is a slightly higher than that of water $\left(0.005-0.05 \mathrm{~S} \cdot \mathrm{m}^{-1}\right)$ but would ensure better permeation of NPs by creating suitable action potential across the biological barriers [71] [72]. Furthermore, density and specific gravity of the tested formulation was $1.035 \pm 0.86 \mathrm{~g} \cdot \mathrm{ml}^{-1}$ and $1.013 \pm 0.27 \mathrm{~g} \cdot \mathrm{ml}^{-3}$ respectively, which is a desirable behaviour of the colloidal solution as it was closer to water. Viscosity of the CGA-NPs was $0.894 \pm 0.9 \mathrm{~Pa} \cdot \mathrm{s}$ which is slightly higher that of blood $0.004 \mathrm{~Pa} \cdot \mathrm{s}$ therefore observed CGA-NPs transportation would face less resistance due to low viscosity [73] [74].

Table 5. Physiochemical parametric analysis of optimised nanoparticles.

\begin{tabular}{cccccc}
\hline & \multicolumn{5}{c}{ Physiochemical Parameters } \\
\cline { 2 - 6 } $\begin{array}{c}\text { Optimised } \\
\text { Nanoparticles }\end{array}$ & $p \mathrm{H}$ & $\begin{array}{c}\text { Conductivity } \\
\left(\mathrm{S} \cdot \mathrm{m}^{-1}\right)\end{array}$ & $\begin{array}{c}\text { Density } \\
\left(\mathrm{g} \cdot \mathrm{ml}^{-1}\right)\end{array}$ & $\begin{array}{c}\text { Specific Gravity } \\
\left(\mathrm{g} / \mathrm{cm}^{3}\right)\end{array}$ & $\begin{array}{c}\text { Viscosity } \\
(\mathrm{Pa} \cdot \mathrm{s})\end{array}$ \\
\cline { 2 - 6 } & $6.7 \pm 0.26$ & $0.221 \pm 0.05$ & $1.035 \pm 0.86$ & $1.013 \pm 0.27$ & $0.894 \pm 0.9$ \\
\hline
\end{tabular}




\subsection{In-Vitro Release Kinetics}

The release kinetics data showed 95.15\% \pm 0.68\% CCR (Cumulative compound release) of CGA from the NPs matrix within 7 hours and only $5 \%$ of it was released in the last 5 hours [75]. The comparative study of the results obtained for release kinetics evaluation of test samples (CGA and CGA-NPs) showed a significant improvement in the release pattern of CGA in case of CGA-NPs (Figure 8). There is a sharp decrease after half-time (at the 6th hour) seen in the release

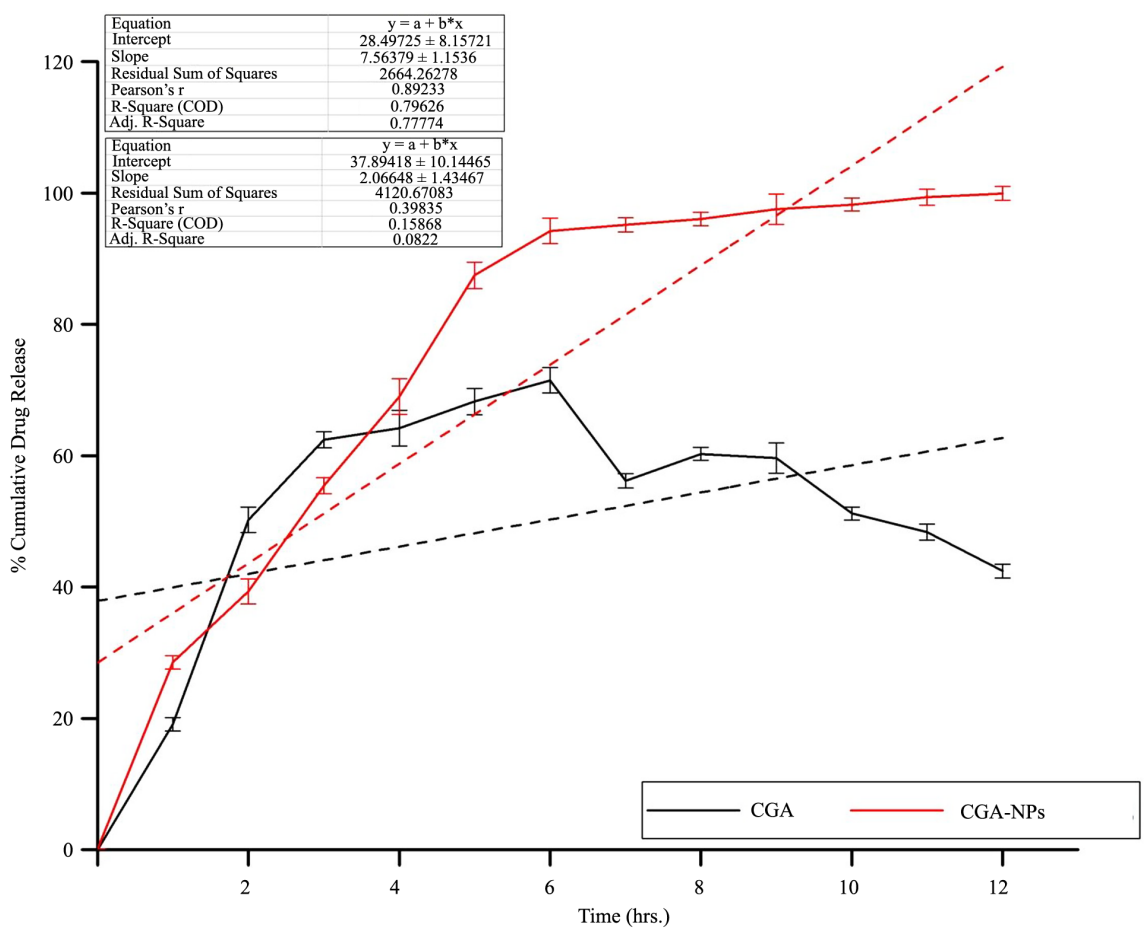

Figure 8. Graph representing the comparative data of cumulative drug release from the CGA and CGA-NPs.

Table 6. Various kinetic models for in-vitro release of CGA and CGA-NPs.

\begin{tabular}{|c|c|c|c|}
\hline & Kinetic Model & Kinetic Model Equation & $\mathbf{R}^{2}$ \\
\hline \multirow{5}{*}{ CGA-NPs } & Zero order & $y=7.5638 x+28.497$ & 0.7963 \\
\hline & First order & $y=-0.1741 x+2.0348$ & 0.9696 \\
\hline & Higuchi's model & $y=0.0295 x+0.0682$ & 0.9353 \\
\hline & Hixson Crowell's model & $y=0.3471 x+0.2052$ & 0.9645 \\
\hline & Korsmeyer-Peppas model & $y=1.128 x+0.9755$ & 0.5895 \\
\hline \multirow{5}{*}{ Pure CGA } & Zero order & $y=2.0665 x+37.894$ & 0.1587 \\
\hline & First order & $y=-0.1391 x+2.1499$ & 0.672 \\
\hline & Higuchi's model & $y=0.0308 x+0.7032$ & 0.3799 \\
\hline & Hixson Crowell's model & $y=0.285 x-0.0172$ & 0.7267 \\
\hline & Korsmeyer-Peppas model & $y=1.0702 x+0.9433$ & 0.5663 \\
\hline
\end{tabular}




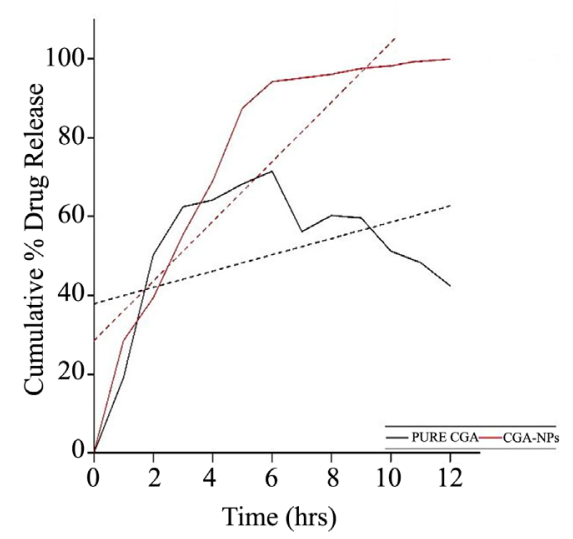

(a)

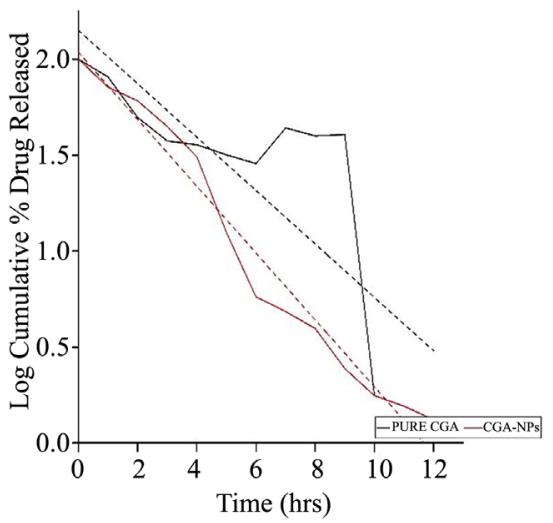

(b)

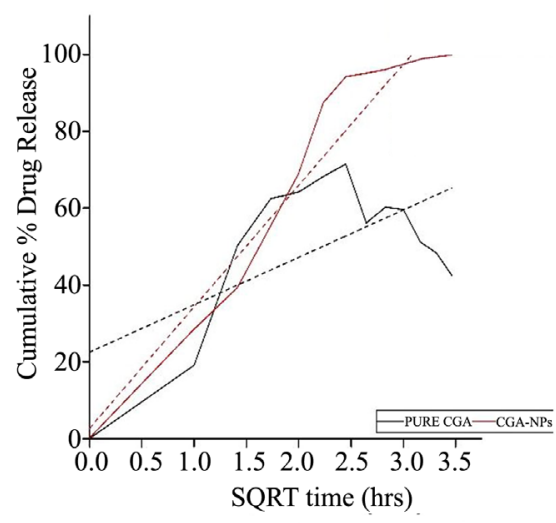

(c)

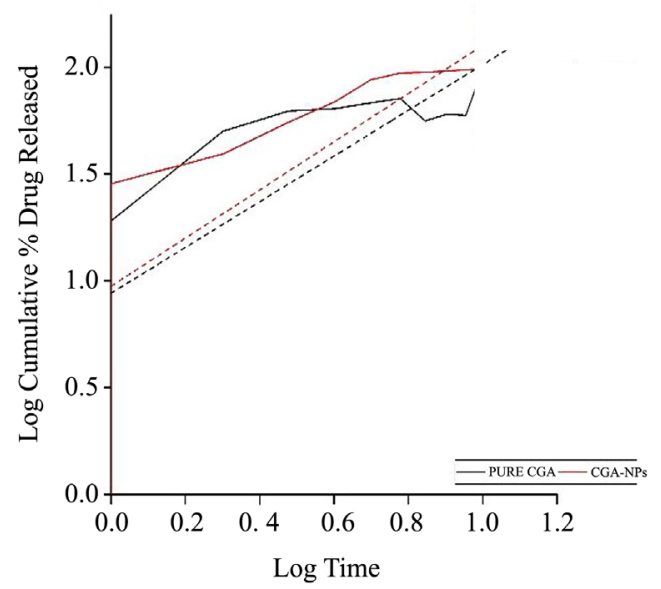

(d)

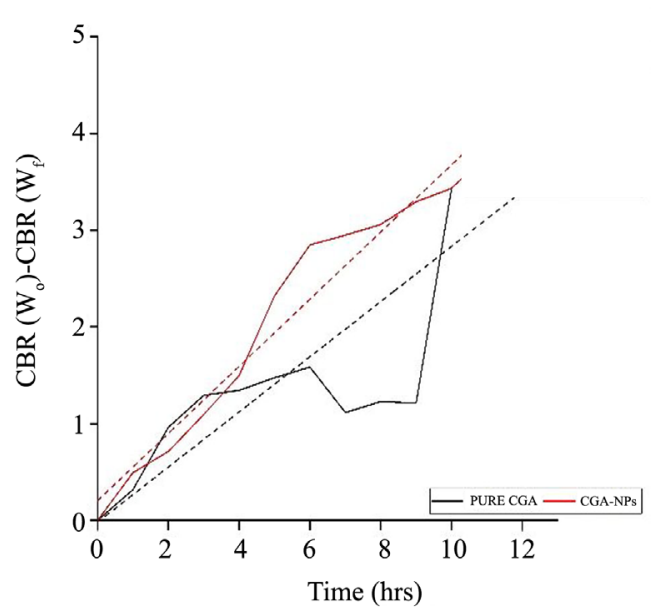

(e)

Figure 9. Kinetic drug release analysis of pure CGA using different models (a) Zero order; (b) First order; (c) Higuchi; (d) KorsPeppas; (e) Hixson model.

of CGA, as opposed to the consistent release pattern seen in case of CGA-NPs [76] [77]. The graph of percentage cumulative compound release versus time validates the sustained release of the drug with time (Figure 8). The verification of CCR data from the standard models of drug release exhibited the rate constant of the equation $\left(\mathrm{R}^{2}=0.9696\right)$ and plot for CGA-NP best fits in the First order model of kinetics (see Table 6, Figure 9). The first order model represents a directly proportional relation between the compound concentration and rate of release, hence following a linear kinetics [78] [79].

\section{Conclusion}

The present study highlights the in-silico validation of high-level interaction of CGA with the active sites of the given proteins (acetylcholine, GSK3 $\beta$, IL-10, Tau protein, $\mathrm{TNF} \alpha$ ) that form the validation of the next step. After the confirmation of their effective binding affinity, synthesis and optimization of CGA-NPs by ionic gelation method was performed and the statistical optimisation for CGA-NPs was done using different parameters, that were varied till the maximum encap- 
sulation efficiency was obtained. Moreover, the optimised set of CGA-NPs had the concentrations of $\mathrm{CH}$ and PCL as $2.5 \%$ and $0.1 \%$, respectively with a sonication time of 10 minutes and a 20 minutes'/ml rate of addition resulting in $99.59 \%$ EE. Furthermore, the optimized CGA-NPs were characterized by different techniques. The optimized CGA-NPs had an average particle size of $101.9 \pm 1.5 \mathrm{~nm}$ with a PDI score of $0.065 \pm 0.02$. The $\mathrm{ZP}$ obtained was $-17.4 \mathrm{mV}$. The results from TEM graphs show that the NPs had a spherical shape and lie in a size range of 90 to $110 \mathrm{~nm}$ which conforms to the results obtained from DLS analyses. The data obtained from comparative evaluation of in-vitro drug release kinetics shows a significant improvement in release profile of CGA in the encapsulated NP form as opposed to the pure form. A sustained release of CGA from the NPs into the media was observed following the First Order model of kinetics (up to 95.15\% of compound released in the initial 7 hours). Thus, these results indicate a successful formulation of CGA-NPs and its ability to treat various NDD diseases and this formulation can be utilised further on suitable in vivo models for testing and verifying their pharmaceutical efficiency.

\section{Acknowledgements}

The research group is thankful to the Department of Biotechnology, Jaypee Institute of Information Technology, JIIT, Noida, U.P., India and SAIF (Sophisticated Analytical Instrumentation Facility), Punjab University Chandigarh, India for providing the facilities to carry to out the research work.

\section{Authors' Contributions}

All authors in the manuscript have contributed equally.

\section{Conflicts of Interest}

The authors declare no conflicts of interest regarding the publication of this paper.

\section{References}

[1] van den Heuvel, M.P. and Sporns, O. (2013) Network Hubs in the Human Brain. Trends in Cognitive Sciences, 17, 683-696. https://doi.org/10.1016/j.tics.2013.09.012

[2] Sweeney, M.D., Kisler, K., Montagne, A., Toga, A.W. and Zlokovic, B.V. (2018) The Role of Brain Vasculature in Neurodegenerative Disorders. Nature Neuroscience, 21, 1318-1331. https://doi.org/10.1038/s41593-018-0234-X

[3] Liebner, S., Dijkhuizen, R.M., Reiss, Y., Plate, K.H., Agalliu, D. and Constantin, G. (2018) Functional Morphology of the Blood-Brain Barrier in Health and Disease. Acta Neuropathologica, 135, 311-336. https://doi.org/10.1007/s00401-018-1815-1

[4] Orhan, I.E. and Akkol, E.K. (2011) Estimation of Neuroprotective Effects of Laurocerasus officinalis Roem. (Cherry Laurel) by in Vitro Methods. Food Research International, 44, 818-822. https://doi.org/10.1016/j.foodres.2011.01.037

[5] Engel, T., Hernández, F., Avila, J. and Lucas, J.J. (2006) Full Reversal of Alzheimer's Disease-Like Phenotype in a Mouse Model with Conditional Overexpression of Glycogen Synthase Kinase-3. Journal of Neuroscience, 26, 5083-5090. 
https://doi.org/10.1523/JNEUROSCI.0604-06.2006

[6] Ji, X., Rivers, L., Zielinski, Z., Xu, M., MacDougall, E., Stephen, J., et al. (2012) Quantitative Analysis of Phenolic Components and Glycoalkaloids from 20 Potato Clones and in Vitro Evaluation of Antioxidant, Cholesterol Uptake, and Neuroprotective Activities. Food Chemistry, 133, 1177-1187. https://doi.org/10.1016/j.foodchem.2011.08.065

[7] Cropley, V., Croft, R., Silber, B., Neale, C., Scholey, A., Stough, C., et al. (2012) Does Coffee Enriched with Chlorogenic Acids Improve Mood and Cognition after Acute Administration in Healthy Elderly? A Pilot Study. Psychopharmacology, 219, 737-749. https://doi.org/10.1007/s00213-011-2395-0

[8] Ahn, E.H., Kim, D.W., Shin, M.J., Kwon, S.W., Kim, Y.N., Kim, D.-S., et al. (2012) Erratum: Chlorogenic Acid Improves Neuroprotective Effect of PEP-1-Ribosomal Protein S3 against Ischemic Insult. Experimental Neurobiology, 21, 172.

https://doi.org/10.5607/en.2012.21.4.172

[9] Ferreira, A., Proença, C., Serralheiro, M. and Araujo, M. (2006) The in Vitro Screening for Acetylcholinesterase Inhibition and Antioxidant Activity of Medicinal Plants from Portugal. Journal of Ethnopharmacology, 108, 31-37.

https://doi.org/10.1016/j.jep.2006.04.010

[10] Singh, S.S., Rai, S.N., Birla, H., Zahra, W., Kumar, G., Gedda, M.R., et al. (2018) Effect of Chlorogenic Acid Supplementation in MPTP-Intoxicated Mouse. Frontiers in Pharmacology, 9, 757. https://doi.org/10.3389/fphar.2018.00757

[11] Kumar, V. (2006) Potential Medicinal Plants for CNS Disorders: An Overview. Phytotherapy Research: An International Journal Devoted to Pharmacological and Toxicological Evaluation of Natural Product Derivatives, 20, 1023-1035. https://doi.org/10.1002/ptr.1970

[12] Patel, T., Zhou, J., Piepmeier, J.M. and Saltzman, W.M. (2012) Polymeric Nanoparticles for Drug Delivery to the Central Nervous System. Advanced Drug Delivery Reviews, 64, 701-705. https://doi.org/10.1016/j.addr.2011.12.006

[13] Khalid, M. and El-Sawy, H.S. (2017) Polymeric Nanoparticles: Promising Platform for Drug Delivery. International Journal of Pharmaceutics, 528, 675-691. https://doi.org/10.1016/j.ijpharm.2017.06.052

[14] Tosi, G., Bortot, B., Ruozi, B., Dolcetta, D., Vandelli, M.A., Forni, F., et al. (2013) Potential Use of Polymeric Nanoparticles for Drug Delivery across the Blood-Brain Barrier. Current Medicinal Chemistry, 20, 2212-2225.

https://doi.org/10.2174/0929867311320170006

[15] Zeng, H.J., Liang, H.L., You, J. and Qu, L.B. (2014) Study on the Binding of Chlorogenic Acid to Pepsin by Spectral and Molecular Docking. Luminescence, 29, 715-721. https://doi.org/10.1002/bio.2610

[16] Naeem, S., Hylands, P. and Barlow, D. (2013) Docking Studies of Chlorogenic Acid against Aldose Redutcase by Using Molgro Virtual Docker Software. Journal of Applied Pharmaceutical Science, 3, 13.

[17] Llorent-Martinez, E.J., Ruiz-Riaguas, A., Sinan, K.I., Bene, K., Fernández-de Cordova, M.L., Picot-Allain, C., et al. (2020) Exploring Chemical Profiles and Bioactivities of Harungana madagascariensis Lam. ex Poir. Leaves and Stem Bark Extracts: A New Source of Procyanidins. Analytical Letters, 53, 399-412. https://doi.org/10.1080/00032719.2019.1653903

[18] Silva, A.B.F., Marinho, M.M. and Mendes, F. (2019) In Silico Study of Phytochemical Chlorogenic Acid: A Semi-Empirical Quantum Study and Adme. International Journal of Recent \& Research and Review, 12, 34-39. 
[19] Kataria, R. and Khatkar, A. (2019) In-Silico Design, Synthesis, ADMET Studies and Biological Evaluation of Novel Derivatives of Chlorogenic Acid against Urease Protein and H. Pylori Bacterium. BMC Chemistry, 13, Article No. 41. https://doi.org/10.1186/s13065-019-0556-0

[20] Kumari, A., Yadav, S.K. and Yadav, S.C. (2010) Biodegradable Polymeric Nanoparticles Based Drug Delivery Systems. Colloids and Surfaces B: Biointerfaces, 75, 1-18. https://doi.org/10.1016/j.colsurfb.2009.09.001

[21] Wilczewska, A.Z., Niemirowicz, K., Markiewicz, K.H. and Car, H. (2012) Nanoparticles as Drug Delivery Systems. Pharmacological Reports, 64, 1020-1037. https://doi.org/10.1016/S1734-1140(12)70901-5

[22] Fan, W., Yan, W., Xu, Z. and Ni, H. (2012) Formation Mechanism of Monodisperse, Low Molecular Weight Chitosan Nanoparticles by Ionic Gelation Technique. Colloids and Surfaces B: Biointerfaces, 90, 21-27. https://doi.org/10.1016/j.colsurfb.2011.09.042

[23] Naahidi, S., Jafari, M., Edalat, F., Raymond, K., Khademhosseini, A. and Chen, P. (2013) Biocompatibility of Engineered Nanoparticles for Drug Delivery. Journal of Controlled Release, 166, 182-194. https://doi.org/10.1016/j.jconrel.2012.12.013

[24] Liu, D., Yang, F., Xiong, F. and Gu, N. (2016) The Smart Drug Delivery System and Its Clinical Potential. Theranostics, 6, 1306. https://doi.org/10.7150/thno.14858

[25] Zhang, Z. and Feng, S.-S. (2006) The Drug Encapsulation Efficiency, in Vitro Drug Release, Cellular Uptake and Cytotoxicity of Paclitaxel-Loaded Poly(lactide)-tocopheryl Polyethylene Glycol Succinate Nanoparticles. Biomaterials, 27, 4025-4033.

https://doi.org/10.1016/j.biomaterials.2006.03.006

[26] Yasir, M. and Sara, U. (2013) Preparation and Optimization of Haloperidol Loaded Solid Lipid Nanoparticles by Box-Behnken Design. Journal of Pharmacy Research, 7, 551-558. https://doi.org/10.1016/j.jopr.2013.05.022

[27] Mahjub, R., Dorkoosh, F.A., Amini, M., Khoshayand, M.R. and Rafiee-Tehrani, M. (2011) Preparation, Statistical Optimization, and in Vitro Characterization of Insulin Nanoparticles Composed of Quaternized Aromatic Derivatives of Chitosan. AAPS Pharmscitech, 12, 1407-1419. https://doi.org/10.1208/s12249-011-9716-9

[28] Damgé, C., Maincent, P. and Ubrich, N. (2007) Oral Delivery of Insulin Associated to Polymeric Nanoparticles in Diabetic Rats. Journal of Controlled Release, 117, 163-170. https://doi.org/10.1016/j.jconrel.2006.10.023

[29] Lee, Y.-L., Kim, M.-S., Park, M.-Y. and Han, K. (2012) Quality by Design: Understanding the Formulation Variables and Optimization of Metformin Hydrochloride 750 mg Sustained Release Tablet by Box-Behnken Design. Journal of Pharmaceutical Investigation, 42, 213-220. https://doi.org/10.1007/s40005-012-0032-5

[30] Elmizadeh, H., Khanmohammadi, M., Ghasemi, K., Hassanzadeh, G., Nassiri-Asl, M. and Garmarudi, A.B. (2013) Preparation and Optimization of Chitosan Nanoparticles and Magnetic Chitosan Nanoparticles as Delivery Systems Using Box-Behnken Statistical Design. Journal of Pharmaceutical and Biomedical Analysis, 80, 141-146. https://doi.org/10.1016/j.jpba.2013.02.038

[31] Sharma, D., Maheshwari, D., Philip, G., Rana, R., Bhatia, S., Singh, M., et al. (2014) Formulation and Optimization of Polymeric Nanoparticles for Intranasal Delivery of Lorazepam Using Box-Behnken Design: In Vitro and In Vivo Evaluation. BioMed Research International, 2014, Article ID: 156010. https://doi.org/10.1155/2014/156010

[32] Sharma, N., Madan, P. and Lin, S. (2016) Effect of Process and Formulation Variables on the Preparation of Parenteral Paclitaxel-Loaded Biodegradable Polymeric Na- 
noparticles: A Co-Surfactant Study. Asian Journal of Pharmaceutical Sciences, 11, 404-416. https://doi.org/10.1016/j.ajps.2015.09.004

[33] Kulkarni, S.A. and Feng, S.-S. (2013) Effects of Particle Size and Surface Modification on Cellular Uptake and Biodistribution of Polymeric Nanoparticles for Drug Delivery. Pharmaceutical Research, 30, 2512-2522. https://doi.org/10.1007/s11095-012-0958-3

[34] Soppimath, K.S., Aminabhavi, T.M., Kulkarni, A.R. and Rudzinski, W.E. (2001) Biodegradable Polymeric Nanoparticles as Drug Delivery Devices. Journal of Controlled Release, 70, 1-20. https://doi.org/10.1016/S0168-3659(00)00339-4

[35] Agnihotri, S.A., Mallikarjuna, N.N. and Aminabhavi, T.M. (2004) Recent Advances on Chitosan-Based Micro- and Nanoparticles in Drug Delivery. Journal of Controlled Release, 100, 5-28. https://doi.org/10.1016/j.jconrel.2004.08.010

[36] He, C., Hu, Y., Yin, L., Tang, C. and Yin, C. (2010) Effects of Particle Size and Surface Charge on Cellular Uptake and Biodistribution of Polymeric Nanoparticles. Biomaterials, 31, 3657-3666. https://doi.org/10.1016/j.biomaterials.2010.01.065

[37] Zhao, W., Huang, J., Fang, B., Nie, S., Yi, N., Su, B., et al. (2011) Modification of Polyethersulfone Membrane by Blending Semi-Interpenetrating Network Polymeric Nanoparticles. Journal of Membrane Science, 369, 258-266.

https://doi.org/10.1016/j.memsci.2010.11.065

[38] Rauwel, P., Küünal, S., Ferdov, S. and Rauwel, E. (2015) A Review on the Green Synthesis of Silver Nanoparticles and Their Morphologies Studied via TEM. Advances in Materials Science and Engineering, 2015, Article ID: 682749. https://doi.org/10.1155/2015/682749

[39] Beganskienè, A., Sirutkaitis, V., Kurtinaitienè, M., Juškènas, R. and Kareiva, A. (2004) FTIR, TEM and NMR Investigations of Stöber Silica Nanoparticles. Materials Science (Medžiagotyra), 10, 287-290.

[40] Sarmento, B., Ferreira, D., Veiga, F. and Ribeiro, A. (2006) Characterization of Insulin-Loaded Alginate Nanoparticles Produced by Ionotropic Pre-Gelation through DSC and FTIR Studies. Carbohydrate Polymers, 66, 1-7. https://doi.org/10.1016/j.carbpol.2006.02.008

[41] Farahnaky, A., Askari, H., Majzoobi, M. and Mesbahi, G. (2010) The Impact of Concentration, Temperature and $\mathrm{pH}$ on Dynamic Rheology of Psyllium Gels. Journal of Food Engineering, 100, 294-301.

https://doi.org/10.1016/j.jfoodeng.2010.04.012

[42] Agarwal, S., Tyagi, V., Agarwal, M., Pant, A., Kaur, H. and Singh, M. (2019) Controllable Transdermal Drug Delivery of Theobroma Cacao Extract Based Polymeric Hydrogel against Dermal Microbial and Oxidative Damage. Food and Nutrition Sciences, 10, 1212-1235. https://doi.org/10.4236/fns.2019.1010088

[43] Bohrey, S., Chourasiya, V. and Pandey, A. (2016) Polymeric Nanoparticles Containing Diazepam: Preparation, Optimization, Characterization, In- Vitro Drug Release and Release Kinetic Study. Nano Convergence, 3, 1-7. https://doi.org/10.1186/s40580-016-0061-2

[44] Dash, S., Murthy, P.N., Nath, L. and Chowdhury, P. (2010) Kinetic Modeling on Drug Release from Controlled Drug Delivery Systems. Acta Poloniae Pharmaceutica, 67, 217-223.

[45] Lee, J.H. and Yeo, Y. (2015) Controlled Drug Release from Pharmaceutical Nanocarriers. Chemical Engineering Science, 125, 75-84.

https://doi.org/10.1016/j.ces.2014.08.046

[46] Barzegar-Jalali, M., Adibkia, K., Valizadeh, H., Shadbad, M.R.S., Nokhodchi, A., 
Omidi, Y., et al. (2008) Kinetic Analysis of Drug Release from Nanoparticles. Journal of Pharmacy and Pharmaceutical Sciences, 11, 167-177. https://doi.org/10.18433/J3D59T

[47] Naveed, M., Hejazi, V., Abbas, M., Kamboh, A.A., Khan, G.J., Shumzaid, M., et al. (2018) Chlorogenic Acid (CGA): A Pharmacological Review and Call for Further Research. Biomedicine \& Pharmacotherapy, 97, 67-74. https://doi.org/10.1016/j.biopha.2017.10.064

[48] Martelli, G. and Giacomini, D. (2018) Antibacterial and Antioxidant Activities for Natural and Synthetic Dual-Active Compounds. European Journal of Medicinal Chemistry, 158, 91-105. https://doi.org/10.1016/j.ejmech.2018.09.009

[49] Bare, Y., Sari, D.R.T., Rachmad, Y.T., Krisnamurti, G.C., Elizabeth, A. and Maulidi, A. (2019) In Silico Insight the Prediction of Chlorogenic Acid in Coffee through Cyclooxygenase-2 (COX2) Interaction. Biogenesis. Jurnal Ilmiah Biologi, 7, 100-105. https://doi.org/10.24252/bio.v7i2.9847

[50] Menin, B., Comino, C., Moglia, A., Dolzhenko, Y., Portis, E. and Lanteri, S. (2010) Identification and Mapping of Genes Related to Caffeoylquinic Acid Synthesis in Cynara cardunculus L. Plant Science, 179, 338-347.

https://doi.org/10.1016/j.plantsci.2010.06.010

[51] Khan, M.T.H., Orhan, I., Şenol, F., Kartal, M., Şener, B., Dvorská, M., et al. (2009) Cholinesterase Inhibitory Activities of Some Flavonoid Derivatives and Chosen Xanthone and Their Molecular Docking Studies. Chemico-Biological Interactions, 181, 383-389. https://doi.org/10.1016/j.cbi.2009.06.024

[52] Lu, S.-H., Wu, J.W., Liu, H.-L., Zhao, J.-H., Liu, K.-T., Chuang, C.-K., et al. (2011) The Discovery of Potential Acetylcholinesterase Inhibitors: A Combination of Pharmacophore Modeling, Virtual Screening, and Molecular Docking Studies. Journal of Biomedical Science, 18, 8. https://doi.org/10.1186/1423-0127-18-8

[53] Ji, H., Tang, J., Li, M., Ren, J., Zheng, N. and Wu, L. (2016) Curcumin-Loaded Solid Lipid Nanoparticles with Brij78 and TPGS Improved in Vivo Oral Bioavailability and in Situ Intestinal Absorption of Curcumin. Drug Delivery, 23, 459-470. https://doi.org/10.3109/10717544.2014.918677

[54] Baig, M.S., Ahad, A., Aslam, M., Imam, S.S., Aqil, M. and Ali, A. (2016) Application of Box-Behnken Design for Preparation of Levofloxacin-Loaded Stearic Acid Solid Lipid Nanoparticles for Ocular Delivery: Optimization, in Vitro Release, Ocular Tolerance, and Antibacterial Activity. International Journal of Biological Macromolecules, 85, 258-270. https://doi.org/10.1016/j.ijbiomac.2015.12.077

[55] Hao, J., Fang, X., Zhou, Y., Wang, J., Guo, F., Li, F., et al. (2011) Development and Optimization of Solid Lipid Nanoparticle Formulation for Ophthalmic Delivery of Chloramphenicol Using a Box-Behnken Design. International Journal of Nanomedicine, 6, 683. https://doi.org/10.2147/IJN.S17386

[56] Shaikh, M.V., Kala, M. and Nivsarkar, M. (2017) Formulation and Optimization of Doxorubicin Loaded Polymeric Nanoparticles Using Box-Behnken Design: Ex-Vivo Stability and In-Vitro Activity. European Journal of Pharmaceutical Sciences, 100, 262-272. https://doi.org/10.1016/j.ejps.2017.01.026

[57] Rahbar, N., Jahangiri, A., Boumi, S. and Khodayar, M.J. (2014) Mercury Removal from Aqueous Solutions with Chitosan-Coated Magnetite Nanoparticles Optimized Using the Box-Behnken Design. Jundishapur Journal of Natural Pharmaceutical Products, 9, e15913. https://doi.org/10.17795/jjnpp-15913

[58] Ribeiro, A.F., Ferreira, C.T.G., dos Santos, J.F., Cabral, L.M. and de Sousa, V.P. (2015) Design of Experiments for the Development of Poly(d, l-lactide-co-glycolide) 
Nanoparticles Loaded with Uncaria tomentosa. Journal of Nanoparticle Research, 17, 69. https://doi.org/10.1007/s11051-015-2883-y

[59] Kumar, A. and Sawant, K. (2013) Encapsulation of Exemestane in Polycaprolactone Nanoparticles: Optimization, Characterization, and Release Kinetics. Cancer Nanotechnology, 4, 57-71. https://doi.org/10.1007/s12645-013-0037-4

[60] Tavares, M.R., de Menezes, L.R., Dutra Filho, J.C., Cabral, L.M. and Tavares, M.I.B. (2017) Surface-Coated Polycaprolactone Nanoparticles with Pharmaceutical Application: Structural and Molecular Mobility Evaluation by TD-NMR. Polymer Testing, 60, 39-48. https://doi.org/10.1016/j.polymertesting.2017.01.032

[61] McDowell, M.T., Ryu, I., Lee, S.W., Wang, C., Nix, W.D. and Cui, Y. (2012) Studying the Kinetics of Crystalline Silicon Nanoparticle Lithiation with in Situ Transmission Electron Microscopy. Advanced Materials, 24, 6034-6041. https://doi.org/10.1002/adma.201202744

[62] Evans, J.E., Jungjohann, K.L., Browning, N.D. and Arslan, I. (2011) Controlled Growth of Nanoparticles from Solution with in Situ Liquid Transmission Electron Microscopy. Nano Letters, 11, 2809-2813. https://doi.org/10.1021/nl201166k

[63] Van der Pol, E., Coumans, F., Grootemaat, A., Gardiner, C., Sargent, I., Harrison, P., et al. (2014) Particle Size Distribution of Exosomes and Microvesicles Determined by Transmission Electron Microscopy, Flow Cytometry, Nanoparticle Tracking Analysis, and Resistive Pulse Sensing. Journal of Thrombosis and Haemostasis, 12, 1182-1192. https://doi.org/10.1111/jth.12602

[64] Gao, T., Ci, Y., Jian, H. and An, C. (2000) FTIR Investigation of the Interaction of Tumor Cells Treated with Caffeic Acid and Chlorogenic Acid. Vibrational Spectroscopy, 24, 225-231. https://doi.org/10.1016/S0924-2031(00)00091-6

[65] Liang, N., Lu, X., Hu, Y. and Kitts, D.D. (2016) Application of Attenuated Total Reflectance-Fourier Transformed Infrared (ATR-FTIR) Spectroscopy to Determine the Chlorogenic Acid Isomer Profile and Antioxidant Capacity of Coffee Beans. Journal of Agricultural and Food Chemistry, 64, 681-689. https://doi.org/10.1021/acs.jafc.5b05682

[66] Ursache, F.-M., Ghinea, I.O., Turturică, M., Aprodu, I., Râpeanu, G. and Stănciuc, N. (2017) Phytochemicals Content and Antioxidant Properties of Sea Buckthorn (Hippophae rhamnoides L.) as Affected by Heat Treatment-Quantitative Spectroscopic and Kinetic Approaches. Food Chemistry, 233, 442-449. https://doi.org/10.1016/j.foodchem.2017.04.107

[67] Nallamuthu, I., Devi, A. and Khanum, F. (2015) Chlorogenic Acid Loaded Chitosan Nanoparticles with Sustained Release Property, Retained Antioxidant Activity and Enhanced Bioavailability. Asian Journal of Pharmaceutical Sciences, 10, 203-211. https://doi.org/10.1016/j.ajps.2014.09.005

[68] Naso, L.G., Valcarcel, M., Roura-Ferrer, M., Kortazar, D., Salado, C., Lezama, L., et al. (2014) Promising Antioxidant and Anticancer (Human Breast Cancer) Oxidovanadium (IV) Complex of Chlorogenic Acid. Synthesis, Characterization and Spectroscopic Examination on the Transport Mechanism with Bovine Serum Albumin. Journal of Inorganic Biochemistry, 135, 86-99. https://doi.org/10.1016/j.jinorgbio.2014.02.013

[69] Alves, P., Pohlmann, A. and Guterres, S. (2005) Semisolid Topical Formulations Containing Nimesulide-Loaded Nanocapsules, Nanospheres or Nanoemulsion: Development and Rheological Characterization. Die Pharmazie-An International Journal of Pharmaceutical Sciences, 60, 900-904.

[70] Mackley, M., Marshall, R., Smeulders, J. and Zhao, F. (1994) The Rheological Cha- 
racterization of Polymeric and Colloidal Fluids. Chemical Engineering Science, 49, 2551-2565. https://doi.org/10.1016/0009-2509(94)E0082-2

[71] Björn, A., de La Monja, P.S., Karlsson, A., Ejlertsson, J. and Svensson, B.H. (2012) Rheological Characterization. Biogas, 1, 63-76. https://doi.org/10.5772/32596

[72] Kole, M. and Dey, T. (2013) Investigation of Thermal Conductivity, Viscosity, and Electrical Conductivity of Graphene Based Nanofluids. Journal of Applied Physics, 113, Article ID: 084307. https://doi.org/10.1063/1.4793581

[73] Shoghl, S.N., Jamali, J. and Moraveji, M.K. (2016) Electrical Conductivity, Viscosity, and Density of Different Nanofluids: An Experimental Study. Experimental Thermal and Fluid Science, 74, 339-346.

https://doi.org/10.1016/j.expthermflusci.2016.01.004

[74] Phuoc, T.X., Massoudi, M. and Chen, R.-H. (2011) Viscosity and Thermal Conductivity of Nanofluids Containing Multi-Walled Carbon Nanotubes Stabilized by Chitosan. International Journal of Thermal Sciences, 50, 12-18.

https://doi.org/10.1016/j.ijthermalsci.2010.09.008

[75] Singhvi, G. and Singh, M. (2011) In-Vitro Drug Release Characterization Models. International Journal of Pharmaceutical Sciences and Research, 2, 77-84.

[76] Fan, Y., Yi, J., Zhang, Y. and Yokoyama, W. (2017) Improved Chemical Stability and Antiproliferative Activities of Curcumin-Loaded Nanoparticles with a Chitosan Chlorogenic Acid Conjugate. Journal of Agricultural and Food Chemistry, 65, 10812-10819. https://doi.org/10.1021/acs.jafc.7b04451

[77] Barahuie, F., Saifullah, B., Dorniani, D., Fakurazi, S., Karthivashan, G., Hussein, M.Z., et al. (2017) Graphene Oxide as a Nanocarrier for Controlled Release and Targeted Delivery of an Anticancer Active Agent, Chlorogenic Acid. Materials Science and Engineering: C, 74, 177-185. https://doi.org/10.1016/j.msec.2016.11.114

[78] Gao, Y., Zuo, J., Bou-Chacra, N., Pinto, T.A., Clas, S.-D., Walker, R.B., et al. (2013) In Vitro Release Kinetics of Antituberculosis Drugs from Nanoparticles Assessed Using a Modified Dissolution Apparatus. BioMed Research International, 2013, Article ID: 136590. https://doi.org/10.1155/2013/136590

[79] Shoaib, M.H., Tazeen, J., Merchant, H.A. and Yousuf, R.I. (2006) Evaluation of Drug Release Kinetics from Ibuprofen Matrix Tablets Using HPMC. Pakistan Journal of Pharmaceutical Sciences, 19, 119-124. 